\title{
Fast Vesicle Replenishment and Rapid Recovery from Desensitization at a Single Synaptic Release Site
}

\author{
John J. Crowley, Adam G. Carter, and Wade G. Regehr \\ Department of Neurobiology, Harvard Medical School, Boston, Massachusetts 02115
}

When the synaptic connection between two neurons consists of a small number of release sites, the ability to maintain transmission at high frequencies is limited by vesicle mobilization and by the response of postsynaptic receptors. These two properties were examined at single release sites between granule cells and stellate cells by triggering bursts of quantal events either with $\alpha$-latrotoxin or with highfrequency trains of presynaptic activity. Bursts and evoked responses consisted of tens to hundreds of events with frequencies of up to hundreds per second. This indicates that single release sites can rapidly supply vesicles from a reserve pool to a release-ready pool. In addition, postsynaptic AMPA receptors recover from desensitization with a time constant of $\sim 5 \mathrm{~ms}$. Thus, even for synapses composed of a single release site, granule cells can effectively activate stellate cells during sustained high-frequency transmission because of rapid vesicle mobilization and fast recovery of AMPA receptors from desensitization.

Key words: desensitization; AMPA; vesicle; reloading; mobilization; latrotoxin;

\section{Introduction}

The frequency range in which synapses can operate is limited by the ability of presynaptic boutons to supply vesicles for release and the ability of postsynaptic cells to respond to neurotransmitter. Because only a small fraction of the vesicles in a bouton are release-ready, prolonged high-frequency stimulation requires replenishment from reserve pools (von Gersdorff and Matthews, 1999; Sudhof, 2004; Kuromi and Kidokoro, 2005; Rizzoli and Betz, 2005). At some types of synapses, vesicle mobilization is thought to be sufficiently slow to cause depletion of release-ready vesicles and short-term depression (von Gersdorff and Matthews, 1997; Schneggenburger et al., 2002; Zucker and Regehr, 2002; Foster and Regehr, 2004; Singer and Diamond, 2006), whereas others refill the release-ready pool rapidly (Griesinger et al., 2005; Saviane and Silver, 2006). For most types of synapses, the capacity of an individual release site to mobilize vesicles from a reserve pool to the release-ready pool remains unknown. On the postsynaptic side, fast excitatory transmission is usually mediated by AMPA receptors (AMPARs), which desensitize in the continued presence of glutamate and usually take tens to hundreds of milliseconds to recover (Dingledine et al., 1999; Mayer and Armstrong, 2004). At synapses where vesicles are released from multiple closely spaced release sites such that glutamate pooling and spillover is prominent, desensitization contributes to synaptic plasticity (Trussell et al., 1993; Isaacson and Walmsley, 1996; Otis

Received Jan. 9, 2007; revised April 10, 2007; accepted April 11, 2007

This work was supported by National Institutes of Health Grant R37 NS032405 (W.G.R.). We thank Claudio Acuna-Goycolea, Michael Beierlein, Aaron Best, Stephan Brenowitz, Megan Carey, Diasynou Fioravante, Kendall Jensen, Andreas Liu, Michael Myoga, and Patrick Safo for comments on this manuscript.

Correspondence should be addressed to Wade G. Regehr, Department of Neurobiology, Goldenson 308, Harvard

Medical School, 220 Longwood Avenue, Boston, MA 02115. E-mail: wade_regehr@hms.harvard.edu.

A. G. Carter's present address: Center for Neural Science, New York University, New York, NY 10003.

DOI:10.1523/JNEUROSCI.1186-07.2007

Copyright $\odot 2007$ Society for Neuroscience $\quad 0270-6474 / 07 / 275448-13 \$ 15.00 / 0$ et al., 1996; Chen et al., 2002; DiGregorio et al., 2002; XuFriedman and Regehr, 2003; Nielsen et al., 2004; Xu-Friedman and Regehr, 2004). In contrast, it remains unclear whether AMPAR desensitization contributes to plasticity at synapses with more isolated release sites (Debanne et al., 1996; Arai and Lynch, 1998; Dittman and Regehr, 1998; Hashimoto and Kano, 1998; Hjelmstad et al., 1999).

Here, we studied transmission at granule cell to stellate cell synapses in rat cerebellar slices. Vesicle replenishment and postsynaptic receptor desensitization are of particular interest at this synapse because granule cells contact stellate cells via a small number of release sites (Palay and Chan-Palay, 1974), they can fire at high frequency in brief bursts (Chadderton et al., 2004) or for sustained periods (Jorntell and Ekerot, 2006), and fusion of a single vesicle can trigger spikes in stellate cells (Carter and Regehr, 2002). The study of single synaptic release sites is ideal for understanding vesicle replenishment and receptor desensitization. We used two approaches to study transmission at individual release sites at this synapse. First, we examined release triggered by $\alpha$-latrotoxin ( $\alpha$-LTX), a peptide from black widow spider venom. $\alpha$-LTX potently triggers vesicle release (Sudhof, 2001; Ushkaryov et al., 2004), which can manifest as bursts of miniature postsynaptic currents from single release sites, as has been shown at inhibitory synapses (Auger and Marty, 1997; Nusser et al., 2001; Rigo et al., 2003). Using the properties of $\alpha$-LTX-evoked bursts to define the behavior of an individual release site, we then extended our study to analyze transmission under more physiological conditions by evoking high-frequency trains of presynaptic activity.

We found that $\alpha$-LTX and stimulus trains evoked bursts of quantal responses that consisted of tens to hundreds of events that occur at high frequencies, indicating that vesicles can be rapidly mobilized for release. Whereas AMPAR desensitization is apparent when two vesicles fuse within several milliseconds, re- 
covery from desensitization occurs rapidly, with a time constant of $5 \mathrm{~ms}$ at $35^{\circ} \mathrm{C}$. Thus, rapid mobilization of vesicles and fast recovery from desensitization make the granule cell to stellate cell synapse well suited to sustain transmission at high frequency, even if the synaptic contact consists of a single release site.

\section{Materials and Methods}

Sagittal and transverse slices (250 $\mu \mathrm{m}$ thick) were prepared from the cerebellar vermis of 16- to 19-d-old Sprague Dawley rats as described previously (Regehr and Mintz, 1994). Slices were superfused at 2-3 ml/ min with an external solution consisting of (in mM) $125 \mathrm{NaCl}, 2.5 \mathrm{KCl}, 2$ $\mathrm{CaCl}_{2}, 1 \mathrm{MgCl}_{2}, 26 \mathrm{NaHCO}_{3}, 1.25 \mathrm{NaH}_{2} \mathrm{PO}_{4}$, and 25 glucose, bubbled with $95 \% \mathrm{O}_{2} / 5 \% \mathrm{CO}_{2}$.

Whole-cell recordings were obtained from visually identified stellate cells in the outer two-thirds of the molecular layer using two to five $\mathrm{M} \Omega$ glass pipettes. The internal solution consisted of (in mM) 35 CsF, 100 $\mathrm{CsCl}, 10$ EGTA, and 10 HEPES, adjusted to $\mathrm{pH} 7.2$ with $\mathrm{CsOH}$. The access resistance and leak current were monitored, and experiments were rejected if either of these parameters increased significantly during the recording. AMPAR-mediated postsynaptic currents were recorded at a holding potential of $-60 \mathrm{mV}$. Bicuculline $(20 \mu \mathrm{M})$ and $5 \mu \mathrm{m} \mathrm{3-}((R)-2-$ carboxypiperazin-4-yl)-propyl-1-phosphoric acid (CPP) were present in all experiments in the bath solution to block $\mathrm{GABA}_{\mathrm{A}}$ receptor-mediated synaptic currents, and NMDA receptor-mediated synaptic currents, respectively. For the experiments with $\alpha$-LTX, $0.5 \mu \mathrm{M}$ tetrodotoxin was present to block voltage-dependent $\mathrm{Na}^{+}$channels.

$\alpha$-LTX (10 nM; Sigma, St. Louis, MO) dissolved in external saline was applied with a picospritzer (PV-820; World Precision Instruments, Sarasota, FL) using a glass pipette $(2-5 \mathrm{M} \Omega) . \alpha$-LTX was puffed onto the molecular layer of a sagittal slice preparation for brief durations $(2-8 \mathrm{~s})$ at $\geq 50 \mu \mathrm{m}$ from the recorded cell. Because $\alpha$-LTX was applied with a short puff and was subsequently diluted, the concentration of $\alpha$-LTX used here was higher than in previous studies in which the toxin was bath applied (0.1-1 nM) (Auger and Marty, 1997; Rigo et al., 2003). Because of the brief and localized nature of the $\alpha$-LTX application, bursts of miniature EPSCs (mEPSCs) were infrequent and typically occurred with a latency of several minutes after a puff. If no bursts were observed in $\sim 5 \mathrm{~min}$ after the first puff, the position of the application pipette was moved and another puff of $\alpha$-LTX was delivered. Bursts of mEPSCs evoked by $\alpha$-LTX could be unambiguously detected because of a dramatically elevated event frequency, typically more than two orders of magnitude higher than the low spontaneous mEPSC frequency $(0.1 \mathrm{~Hz} ; n=6)$ (see Fig. 1), or the interburst frequency after the application of $\alpha$-LTX (1.5 \pm $0.3 \mathrm{~Hz} ; n=48)$. Across all experiments, the ratio of the burst frequency to the spontaneous mEPSC frequency of the preceding interburst interval was $175 \pm 50(n=48)$. Any overlapping bursts were excluded from the analysis. For the extracellular stimulation, a pair of 5-10 $\mathrm{M} \Omega$ glass pipettes filled with external saline was placed either in the molecular layer or the granule cell layer at $\geq 50 \mu \mathrm{m}$ from the recorded cell in a transverse slice preparation. Trains of stimuli were delivered every $60 \mathrm{~s}$. Poisson trains [ $\sim 200 \mathrm{~Hz}$; minimum interstimulus interval (ISI), $2.5 \mathrm{~ms}$ ] were interleaved with regular trains $(100 \mathrm{~Hz})$ to allow study of very shortlatency events. The stimulus intensity was set just above the threshold for evoking events during the train to minimize the likelihood of recruiting $>1$ input onto the stellate cell. Under these conditions, the onset of the EPSCs during the train was variable and some trials produced no events during the train.

Outputs from an Axopatch 200A (Molecular Devices, Foster City, CA) amplifier were digitized with an ITC-18 A/D converter (Instrutech, Great Neck, NY) using custom routines (written by M. A. Xu-Friedman, State University of New York, Buffalo, NY) in Igor Pro (Wavemetrics, Lake Oswego, OR). Recordings were sampled at $25-100 \mathrm{kHz}$ and filtered at $2.5-5 \mathrm{kHz}$. Experiments were performed at either room temperature $\left(22-24^{\circ} \mathrm{C}\right)$ or near physiological temperature $\left(34-36^{\circ} \mathrm{C}\right)$ as indicated. Experiments with $\alpha$-LTX were performed in presence of external $\mathrm{CaCl}_{2}$ concentrations of $0.5-4 \mathrm{~mm}$ in an attempt to systematically vary the intraburst event frequency. However, variations in external $\mathrm{CaCl}_{2}$ did not significantly influence event number $(p=0.18)$, frequency $(p=$
0.58 ), or amplitude ( $p=0.98$ ) and results were pooled. All extracellular stimulation experiments were performed in $2 \mathrm{mM} \mathrm{CaCl}_{2}$ at $34-36^{\circ} \mathrm{C}$. All chemicals were from Sigma except CPP, 1,2,3,4-tetrahydro-6-nitro-2,3dioxo-benzo[f]quinoxaline-7-sulfonamide (NBQX), DL-threobenzyloxyaspartic acid (TBOA), cyclothiazide (CTZ), and $\gamma$-Dglutamylglycine (DGG) (Tocris Cookson, Ellisville, MO).

The detection of postsynaptic currents was accomplished by setting a detection threshold for the first derivative of the current trace and using these level crossings to search for event peaks on the raw current trace. The minimal threshold for detection of events from the raw current trace was typically $5-15$ pA. For pairs of overlapping events, the amplitude of the second event was determined by scaling the average mEPSC waveform to the peak of the first event and subtracting it from the current trace (see Fig. $3 D$ ). Closely spaced events could be detected reliably provided they were separated by at least $150 \mu \mathrm{s}$. For $\alpha$-LTX-evoked bursts, the number of events plotted versus interevent interval $(\Delta t)$ was well approximated by an exponential except that for $0<\Delta t<500 \mu$ s there were fewer events than expected. If we attribute this deviation to our inability to detect closely spaced events, we estimate that we miss $<1 \%$ of the events during a burst, which would not significantly alter our conclusions. For stimulation trains, we estimate the fraction of events that we are unable to detect based on the peristimulus time histogram $[p(t)]$ by taking the weighted average of the probability of having two events within a $300 \mu \mathrm{s}$ bin $\left[p(t)^{2}\right]$. Using this approach, we estimate that we fail to detect $1.3 \pm 0.5 \%(n=13)$ of the events. To summarize data across bursts or stimulus trains, the event amplitudes in each burst or train were normalized to the average amplitude for events in that burst or train separated by at least $20 \mathrm{~ms}$. For the extracellular stimulation, only experiments in which the coefficient of variation for these well separated events was $<0.35$ were considered for additional analysis $(n=13)$. This coefficient of variation corresponds to the values observed for bursts recorded under the same experimental conditions $\left(2 \mathrm{CaCl}_{2}, 35^{\circ} \mathrm{C}\right.$; range, $0.17-0.4$; mean, $0.29 \pm 0.02)$. The normalized amplitudes and corresponding $\Delta t$ values from each burst or train were combined. The events were sorted by $\Delta t$ value into 16 logarithmic bins across a range from 0.1 to $100 \mathrm{~ms}$, and the average normalized amplitude was determined. Bins containing less than three events were not included in the analysis. Analysis was performed using Igor Pro software (Wavemetrics). Data are expressed as mean \pm SEM, except for time constant and amplitude values from exponential fits, which are mean \pm SD. Statistical significance was determined with $t$ tests and with single-factor ANOVA tests.

\section{Results}

\section{$\alpha$-LTX triggers bursts of mEPSCs from single sites}

To study vesicle mobilization and AMPAR desensitization at single release sites, we first set out to determine whether $\alpha$-LTX can trigger bursts from individual glutamatergic release sites, as has been observed for GABAergic synapses onto stellate cells (Auger and Marty, 1997). mEPSCs in stellate cells are large and readily detected, and their low frequency makes them ideal for studying single release sites with $\alpha$-LTX. This is evident in a representative recording from a stellate cell of spontaneous AMPAR-mediated mEPSCs collected at $35^{\circ} \mathrm{C}$ (Fig. $1 \mathrm{~A}$ ). Across cells, these events occur at a low average frequency of $0.12 \pm 0.01 \mathrm{~Hz}(n=6)$. The relative ease with which the amplitudes and decay time constants of mEPSCs can be determined provides an important means of characterizing mEPSCs during bursts and assessing whether they arise from a single release site. A high degree of scatter in a plot of the amplitude versus decay time constant for each spontaneous mEPSC collected over a $10 \mathrm{~min}$ period indicates a large variation in these parameters (Fig. $1 B$ ). The coefficient of variation $(\mathrm{CV})$ among spontaneous events in these recordings is $0.67 \pm 0.05$ $(n=6)$ for mEPSC amplitudes and $0.47 \pm 0.06(n=6)$ for the decay time constants. The large degree of heterogeneity of the spontaneous events suggests that they arise from multiple release sites onto the recorded cell.

The application $\alpha$-LTX (10 nM) to the slice produced discrete 
bursts of tens to hundreds of mEPSCs at $35^{\circ} \mathrm{C}$ (Fig. 1C) and at room temperature (Fig. $1 E$ ). Bursts of mEPSCs were observed with a latency of several minutes after a brief puff of the toxin onto the molecular layer (see Materials and Methods). Several lines of evidence suggest that mEPSCs during a burst arise from a single release site. First, the events within a burst exhibit a lower variation in amplitude and decay time constant relative to spontaneous mEPSCs (Fig. 1D,F). The CV values for mEPSC amplitude $(0.29 \pm 0.02 ; n=17)$ and decay time constant $(0.18 \pm 0.01 ; n=$ 17) within a burst are significantly lower than those observed for spontaneous events $\left(p<0.001 ; 35^{\circ} \mathrm{C}\right)$. The relatively small variability of event amplitude and decay time within a burst is consistent with the involvement of a single synaptic release site. Second, as shown in detail in subsequent figures, the mEPSC amplitude depends on the interevent interval within a burst. This observation indicates that each mEPSC within a burst is activating the same population of AMPARs and is inconsistent with events arising from multiple, independent release sites. Third, because granule cell boutons are separated by $\sim 5$ $\mu \mathrm{m}$ and typically contain a single release site (Xu-Friedman et al., 2001; Shepherd and Raastad, 2003), it is highly likely that an isolated burst reflects the effect of $\alpha$-LTX on a single release site. Fourth, the average frequency attained within a burst is markedly higher than observed for spontaneous mEPSCs, suggesting that contamination by events from other sites is minimal. $\alpha$-LTX-triggered bursts exhibit an average frequency of $17 \pm 3 \mathrm{~Hz}(n=23)$ at $24^{\circ} \mathrm{C}$, which increases to $47 \pm 5 \mathrm{~Hz}(n=48)$ at $35^{\circ} \mathrm{C}$. Overall, these observations indicate that $\alpha$-LTX triggers bursts of mEPSCs from individual glutamatergic release sites.

\section{Rapid vesicle mobilization occurs at single release sites}

The frequency of mEPSCs during an $\alpha$-LTX-induced burst provides insight into the ability of the bouton to mobilize vesicles for release. Release triggered by $\alpha$-LTX requires functional SNARE (soluble $\mathrm{N}$-ethylmaleimide-sensitive factor attachment protein receptor) proteins (Capogna et al., 1997; Sudhof, 2001), suggesting that endogenous pathways for mobilizing and docking vesicles are involved, but appears to act upstream of late priming steps (Augustin et al., 1999) and calcium triggering (Khvotchev et al., 2000; Sudhof, 2001). A burst of mEPSCs with a particularly high average frequency, consisting of $>80$ events occurring within $\sim 1 \mathrm{~s}(83 \mathrm{~Hz})$, is shown in Figure $2 A$. In an expanded view of the burst (Fig. $2 B$ ), it is evident that the interevent interval $(\Delta t)$ is variable, and can be short enough that successive events overlap despite the rapid decay of the $\mathrm{mEPSC}(\tau=0.72 \mathrm{~ms})$. A histogram of $\Delta t$ values within a burst at a single site is well approximated by a single exponential, indicating that events show a Poisson distribution (Fig. 2C). The average mEPSC frequency within a burst is much higher than that observed for spontaneous mEPSCs, and is generally tens to hundreds of Hertz (Fig. 2D). The average burst frequency was $>30$-fold higher than the average preburst mEPSC frequency in the presence of $\alpha$-LTX $(47 \pm 5 \mathrm{~Hz}$ vs $1.5 \pm 0.3 \mathrm{~Hz}$; $n=48)$. When calculated for each individual burst, the ratio of the burst frequency to the frequency of events preceding the burst was on average $175 \pm 50(n=48)$, suggesting that $<1 \%$ of the events in a burst arise from other release sites. A plot of $\Delta t$ versus event number averaged across bursts at $24^{\circ} \mathrm{C}(n=17)$ (Fig. $2 E$, open gray circles) and a corresponding running average (Fig. $2 E$, filled gray circles) indicate that the latency between events increases during the course of a burst at this temperature. The reason for this decrease in event frequency during bursts at $24^{\circ} \mathrm{C}$ is not understood. One possibility is that it could indicate the depletion of a release-ready pool, but it may also reflect the activation triggered by $\alpha$-LTX. However, at $35^{\circ} \mathrm{C}(n=48)$ (Fig. $2 E$, black circles) no change in the average latency is observed and release can be maintained at high frequency for many events with no diminution in release rate. Overall, $\alpha$-LTX-triggered bursts vary in number of events from tens to hundreds (average, $90 \pm 8$; $n=48$ ) and there is no obvious correlation between number of events in a burst and the average burst frequency $(47 \pm 5 \mathrm{~Hz})$ (Fig. 2F).

The large number of events in a burst suggests that single sites can rapidly mobilize large numbers of synaptic vesicles for re- 

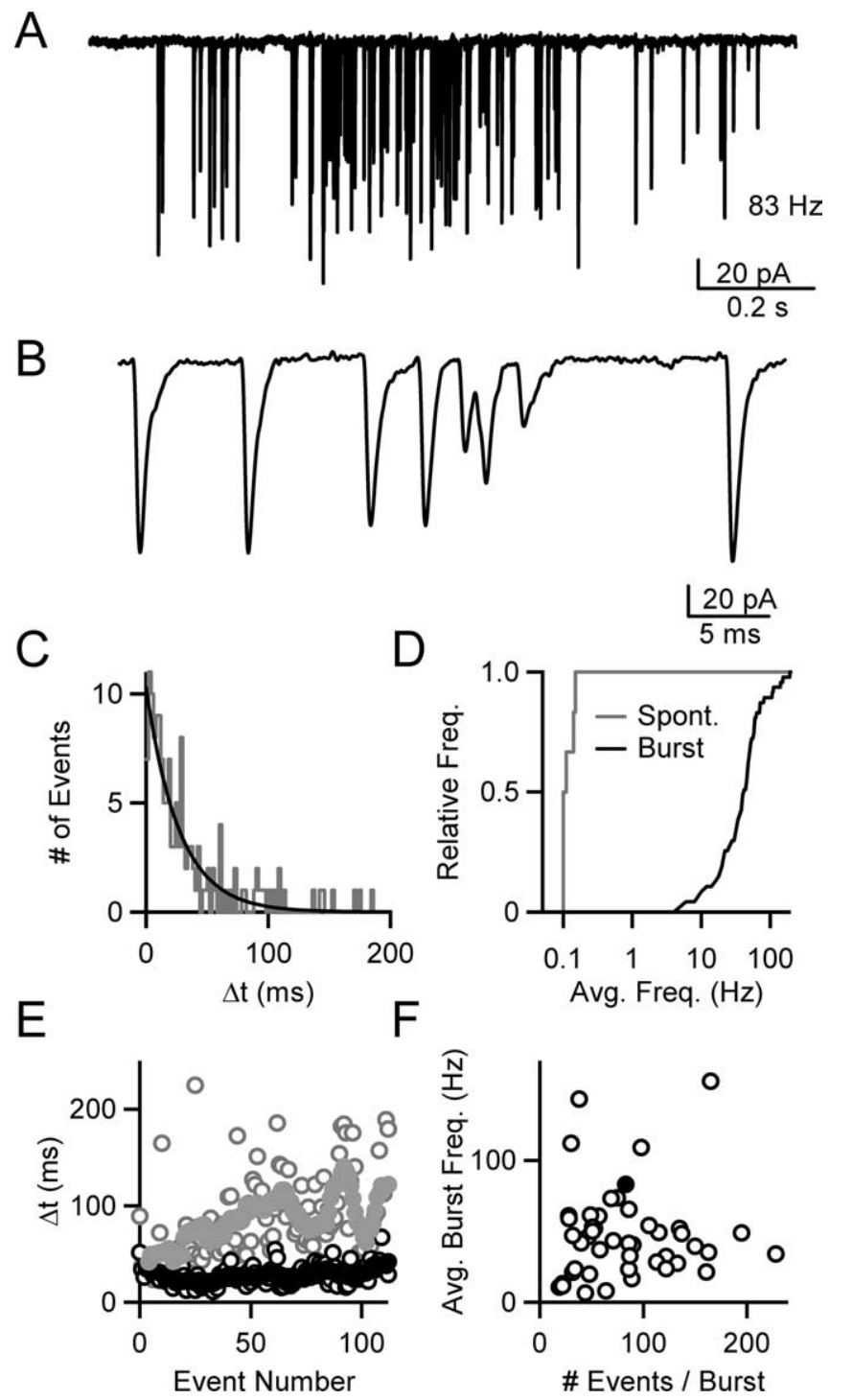

Figure 2. Single active zones can release large numbers of vesicles at high frequency. $\boldsymbol{A}$, Representative recording of an $\alpha$-LTX-triggered burst of mEPSCs recorded from a stellate cell $\left(35^{\circ} \mathrm{C}, 4 \mathrm{Ca}_{\mathrm{e}}\right) \cdot \boldsymbol{B}$, Expanded view of the burst shown in $\boldsymbol{A}$ demonstrating that the instantaneous frequency can reach several hundred Hertz. $C$, Histogram of interevent intervals $(\Delta t)$ within a representative burst, fit with a single exponential ( $\tau=27 \mathrm{~ms}$ ). $\boldsymbol{D}$, Cumulative histogram comparing the average frequency of spontaneous mEPSCs (gray line; $n=6$ cells) and $\alpha$-LTX bursts of $\mathrm{mEPSCs}$ (black line; $n=48$ bursts). $\boldsymbol{E}$, Plot of the average $\Delta t$ (open circles) versus event number for bursts collected at $24^{\circ} \mathrm{C}$ (gray; $n=17$ bursts) and at $35^{\circ} \mathrm{C}$ (black; $n=48$ bursts). The running averages (10 point) for each are shown superimposed on the data (filled circles). F, Plot of the average burst frequency during a burst versus the number of events in a burst $\left(35^{\circ} \mathrm{C}\right)$. Data from mEPSC bursts in several conditions are summarized: control $(n=17), 100 \mu \mathrm{M} \mathrm{CTZ}(n=6), 100 \mu \mathrm{m} \mathrm{CTZ}$ plus $2 \mathrm{~mm} \mathrm{DGG}(n=10), 1 \mathrm{~mm} \mathrm{DGG}(n=6)$, and $100-300 \mu \mathrm{m} \mathrm{TBOA}(n=8)$. The burst shown in $A$ is denoted by the filled circle. There is no significant difference between groups in the event frequency of $\alpha$-LTX-evoked bursts recorded under these conditions (ANOVA, $p=0.48$ ).

lease. Bursts of mEPSCs triggered by $\alpha$-LTX consist of 90 events on average, yet ultrastructural studies indicate that granule cell boutons contain an average of seven to eight morphologically docked vesicles (Xu-Friedman et al., 2001). Although ultrastructural data are only available for boutons associated with Purkinje cells, the similarity in the facilitation and delayed release of granule cell synapses onto Purkinje cells and stellate cells suggests that the presynaptic properties of these synapses are remarkably similar (Atluri and Regehr, 1998). This suggests that at granule cell boutons onto stellate cells vesicles must be mobilized from a reserve pool during bursts. The high frequencies of mEPSCs during bursts indicate that individual sites have a remarkable capacity for vesicle mobilization and that $10-100$ vesicles can be rapidly transferred to the release-ready pool. The average burst frequency of $47 \mathrm{~Hz}$ at $35^{\circ} \mathrm{C}$ provides an estimate of $21 \mathrm{~ms}$ for the time taken to mobilize vesicles from a reserve to the release-ready pool. This is a reasonable estimate because the average event latency remains constant during the course of a burst at this temperature (Fig. 2E).

\section{mEPSC amplitude within a burst depends on} release frequency

Bursts triggered by $\alpha$-LTX allow a direct measurement of synaptic responses at a single release site. A subset of events from a representative burst, which are separated by a $\Delta t$ of at least $10 \mathrm{~ms}$, are shown superimposed in Figure $3 A$. The amplitude histogram (average, $93 \mathrm{pA}$ ) (Fig. 3B) and decay time constant histogram (average, $0.75 \mathrm{~ms}$ ) (Fig. $3 \mathrm{C}$ ) for this subset of well isolated mEPSCs exhibit a Gaussian distribution. This distribution of event amplitudes is consistent with the distribution of mPSCs from single release sites at several, but not all, central synapses (Bekkers and Stevens, 1995; Liu and Tsien, 1995; Silver et al., 1996; Auger and Marty, 1997; Forti et al., 1997; Nusser et al., 2001). The average CV value for mEPSC amplitude within a burst is $0.29 \pm 0.02(n=17)$. Whereas the variation in amplitude within a burst is significantly lower than for spontaneous mEPSCs (CV, $0.67 \pm 0.05 ; n=6 ; p<0.001$ ) (Fig. 1), the CV values are higher than those reported previously at inhibitory synapses onto stellate cells $(0.14 \pm 0.05)$ (Auger and Marty, 1997). The higher CV values suggest that, in stellate cells, a single vesicle of glutamate results in a lower occupancy of AMPARs than is typical of $\mathrm{GABA}_{\mathrm{A}}$ receptors after quantal GABA release.

$\alpha$-LTX bursts allow an analysis of synaptic responses during very rapid bouts of vesicle release, from which the frequency dependence of mEPSC amplitude can be assessed. Figure 3D shows an example of two successive mEPSCs in a burst with a very brief $\Delta t$, and a schematic illustrating the correction to determine mEPSC amplitude when $\Delta t$ is small and events overlap (see Materials and Methods). This overlap occurs when $\Delta t$ is shorter than the decay time for an mEPSC, which is very rapid in stellate cells (average, $0.72 \mathrm{~ms}$ ) (Fig. 3E). The average mEPSC for each burst, obtained from the plot in Figure $3 A$, is shown normalized and superimposed in Figure $3 E$ (gray traces), along with the average across all bursts (black trace). The decay of the average mEPSC across all bursts is approximated by a single exponential with a time constant of $0.720 \pm 0.003 \mathrm{~ms}\left(35^{\circ} \mathrm{C}\right)$.

We examined the frequency dependence of mEPSC amplitude, which can arise through use-dependent processes such as AMPAR saturation or desensitization by plotting the mEPSC amplitude as a function of $\Delta t$. AMPAR saturation or desensitization can occur when released vesicles interact with a single population of postsynaptic receptors, and would result in a decrease in mEPSC amplitude at short latency. This is indeed evident in a plot of mEPSC amplitude versus $\Delta t$ for a representative burst (Fig. $3 F$ ). An accurate quantitation of the dependence of mEPSC amplitude on $\Delta t$ was difficult to obtain for some individual bursts because of the lack of a sufficient number of events at very short latencies. Therefore, we determined the frequency dependence of synaptic responses at a single site by compiling events from all bursts recorded under the same conditions (see Materials and Methods). Across all individual release sites, the mEPSC amplitude within a burst was indeed reduced if it followed another mEPSC with short latency. At $35^{\circ} \mathrm{C}(n=17$ bursts; 1184 events), 
the data are well approximated by a single exponential with a time constant of $4.8 \pm$ $0.2 \mathrm{~ms}$ (Fig. 3G, dotted line), consistent with the involvement of a single population of postsynaptic receptors. The synaptic responses maintain a high fidelity across a broad range of $\Delta t$ values, decreasing only when the instantaneous frequency $(1 / \Delta t)$ surpasses $100 \mathrm{~Hz}$. The magnitude of the reduction in mEPSC amplitude at $\Delta t=0$ obtained from the fit is $32 \pm 1 \%$.

The reduction in mEPSC amplitude at short latencies could be caused by high occupancy of postsynaptic receptors and/or receptor desensitization. Insight into these possibilities can be gained by comparing the time course of the recovery of mEPSC amplitude to that of the decay of the mEPSC. If saturation of the postsynaptic receptors is the predominant cause of the reduction in mEPSC amplitude at short latency, the time course of the recovery of mEPSC amplitude should match the time course of mEPSC decay, as has been shown for single inhibitory synapses onto stellate cells (Auger and Marty, 1997). Figure 3H compares the decay of the average mEPSC at $35^{\circ} \mathrm{C}$ (solid line) to the recovery of mEPSC amplitude with $\Delta t$ (open boxes), where both are normalized to the same time point. The recovery of $\mathrm{mEPSC}$ amplitude ( $\tau=4.8 \mathrm{~ms}$, dotted line) outlasts the decay of the mEPSC ( $\tau=0.72 \mathrm{~ms})$, suggesting that postsynaptic receptor saturation alone cannot account for the reduction of the mEPSC amplitude. A similar relationship is observed at $24^{\circ} \mathrm{C}(n=17$ bursts; 1250 events), where the mEPSC decays with $\tau=1.000 \pm 0.004 \mathrm{~ms}$ (Fig. 3I, solid line) and the reduction in mEPSC amplitude (open boxes) is approximated by a doubleexponential function, with $\tau_{1}=0.80 \mathrm{~ms}$ and $\tau_{2}=20 \mathrm{~ms}$ (Fig. 3I, dotted line).

These data indicate that single sites can maintain highfrequency transmission with remarkable fidelity. Use-dependent decreases in mEPSC amplitude are only apparent when the frequency of vesicle release is extremely rapid. Moreover, the time course of the recovery of mEPSC amplitude suggests that saturation alone is not sufficient and that receptor desensitization may play a role.

\section{Receptor desensitization contributes to the frequency- dependent reduction in $\mathrm{mEPSC}$ amplitude at a single release site}

We next examined the contribution of AMPA receptor desensitization to the reduction in mEPSC amplitude observed with decreases in $\Delta t$. Bursts of mEPSCs triggered by $\alpha$-LTX were col-

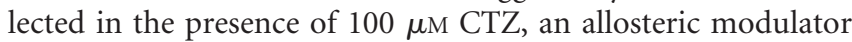
that prevents receptor desensitization and enhances the apparent affinity of AMPARs for glutamate (Patneau et al., 1993; Yamada and Tang, 1993). A portion of a representative burst collected at $35^{\circ} \mathrm{C}$ in the presence of $100 \mu \mathrm{M} \mathrm{CTZ}$ is shown in Figure $4 \mathrm{~A}$. With
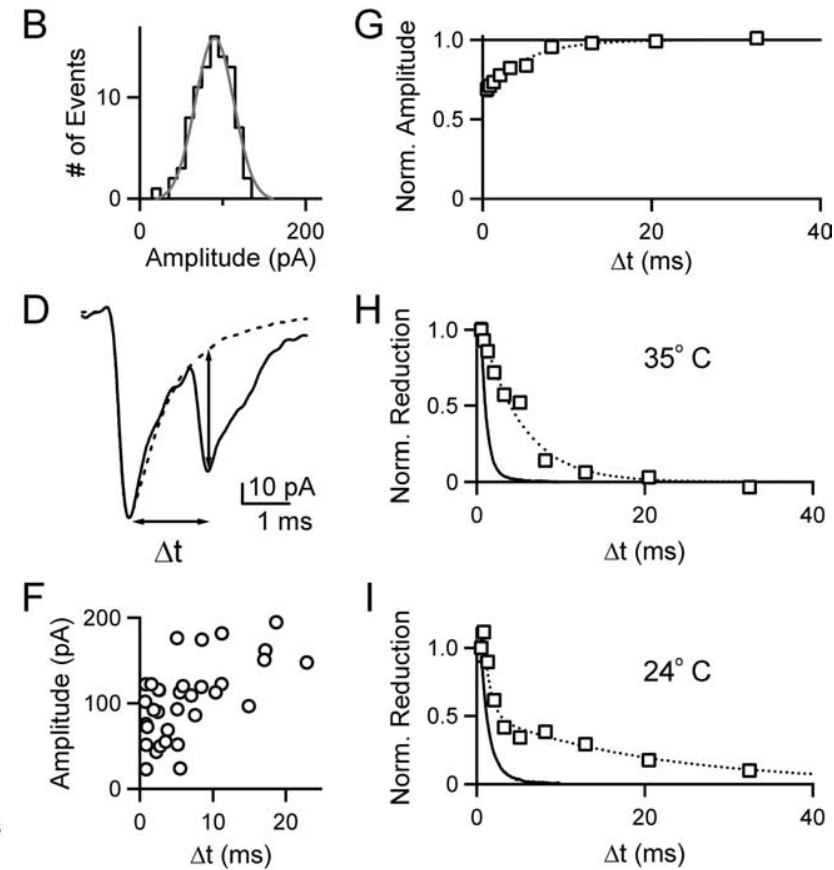

Figure 3. Postsynaptic AMPAR responses are reduced as the interevent interval decreases, and the reduction outlasts the decay

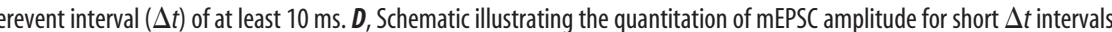
mplitude versus $\Delta t$ across all bursts recorded in control conditions at $35^{\circ} \mathrm{C}(n=17$ bursts; 1184 events). The amplitude for each the burst is normalized to the avage mEPSC amplitude for events with a $\Delta t \geq 20 \mathrm{~ms}$, and the events are binned ( after the peak). The decay of the average $m$ EPSC is well fit by the equation $m E P S C$ decay $=A \exp (-\Delta t / \tau)$, with fit parameters $[A, \tau(\mathrm{ms})]$ of $[1.1,0.72]$. $I$, Plot comparing the time constant for the reduction in mEPSC amplitude with $\Delta t$ (open boxes) to the (he course of the average mEPSC (solid line) at $24^{\circ} \mathrm{C}(n=17$ bursts; 1250 events). The decay of the average mEPSC is well (dotted line) by the following equation: normalized amplitude $=A_{1} \exp \left(-\Delta t / \tau_{1}\right)+A_{2} \exp \left(-\Delta t / \tau_{2}\right)$ with fit parameters $\left[A_{1}\right.$ $\left.A_{2}, \tau_{1}(\mathrm{~ms}), \tau_{2}(\mathrm{~ms})\right]$ of $[0.30,0.18,0.80,20]$.

CTZ present, the amplitude of mEPSCs in the burst appears to saturate during rapid bouts of release. The average mEPSC amplitude for bursts collected in the presence of CTZ $(190 \pm 33 \mathrm{pA}$; $n=6$ bursts) is significantly larger than for control bursts ( $79 \pm$ $10 \mathrm{pA} ; n=17 ; p<0.005)$. In addition, the time course of decay of the mEPSC is markedly slowed in the presence of CTZ, and the average mEPSC across all bursts under these conditions (Fig. $4 B$, black trace) is approximated by a double exponential with $\tau_{1}=$ $1.1 \mathrm{~ms}$ and $\tau_{2}=5.0 \mathrm{~ms}$. These actions of CTZ are consistent with an increase in the apparent affinity of AMPARs for glutamate.

The relationship between amplitude and $\Delta t$ for the representative burst is shown in Figure $4 C$, with a reduction in mEPSC amplitude apparent despite the variation in mEPSC amplitude. This is likely attributed to the slower mEPSC decay, and the apparent saturation of the responses in the presence of CTZ. A summary for all bursts recorded in $100 \mu \mathrm{M} \mathrm{CTZ}$ at $35^{\circ} \mathrm{C}(n=6$ bursts; 600 events) is shown in Figure $4 D$, along with a singleexponential fit of the data (dotted line; $\tau=5.1 \pm 0.4 \mathrm{~ms}$ ). If, under control conditions, desensitization contributes to the slow 
recovery of mEPSC amplitude relative to mEPSC decay, when desensitization is prevented with CTZ mEPSC amplitude should recover with a time course that matches the time course of mEPSC decay. Figure $4 E$ compares the decay of the average mEPSC in CTZ at $35^{\circ} \mathrm{C}$ (black trace) to the reduction in mEPSC amplitude with $\Delta t$ in CTZ (open boxes), both normalized to the same time point. The reduction in mEPSC amplitude $(\tau=5.1$ ms; dotted line) closely tracks the decay of the mEPSC $\left(\tau_{1}=1.1\right.$; $\left.\tau_{2}=5.0 \mathrm{~ms}\right)$. This relationship persists at room temperature $(n=$ 5 bursts; 507 events) (Fig. $4 F$ ), where both the decay of the $\operatorname{mEPSC}\left(\tau_{1}=2.3 ; \tau_{2}=12 \mathrm{~ms}\right.$; solid line $)$ and the time course for the recovery of mEPSC amplitude ( $\tau=13 \mathrm{~ms}$; open boxes; dotted line) are slower, but more closely aligned. These data, together with Figure 3, suggest that AMPA receptor desensitization contributes to the reduction in mEPSC amplitude under control conditions when the latency between events in a burst is short.

\section{Reducing AMPA receptor occupancy with a low-affinity antagonist dramatically reduces the dependence of mEPSC amplitude on $\Delta t$}

The magnitude of the decrease in mEPSC amplitude for closely spaced events during $\alpha$-LTX bursts suggests that a single vesicle releases enough glutamate to bind and desensitize a significant fraction of AMPARs. With desensitization blocked by CTZ, the reduction in mEPSC amplitude matches closely the decay of the average mEPSC, suggesting it is attributed to a near saturation of the postsynaptic receptors under those conditions. We next examined the dependence of mEPSC amplitude on $\Delta t$ when both desensitization and saturation are prevented by decreasing AMPAR occupancy with the low-affinity AMPAR antagonist DGG. DGG and glutamate compete for binding sites on the AMPAR, with the low affinity of DGG for the AMPAR leading to a very rapid off-rate. The rapid re-equilibration of DGG-blocked and available receptors makes the extent of DGG inhibition sensitive to the concentration of glutamate in the synaptic cleft, and allows successive mEPSCs to be mediated by different receptors in the postsynaptic density. As a result, DGG can relieve the effects of saturation and desensitization on the postsynaptic AMPARs (Wadiche and Jahr, 2001; Wong et al., 2003; Foster and Regehr, 2004).

We examined the time dependence of mEPSC amplitude for bursts recorded in the presence of CTZ and DGG, and also for bursts collected in DGG alone. As expected, mEPSC amplitudes were smaller in the presence of $100 \mu \mathrm{M} \mathrm{CTZ}$ and $2 \mathrm{mM}$ DGG than in $100 \mu \mathrm{M} \mathrm{CTZ}$ alone $(87 \pm 14 \mathrm{pA}, n=10$ compared with $191 \pm$ $33 \mathrm{pA}, n=6 ; p<0.05)$. In the presence of $100 \mu \mathrm{M} \mathrm{CTZ}$ and $2 \mathrm{~mm}$ DGG, mEPSCs were additive during rapid bouts of vesicle release (Fig. $4 G$ ), in contrast to bursts in CTZ alone, which exhibited saturation (Fig. 4A). Most importantly, the dependence of mEPSC amplitude on $\Delta t$ was abolished in $100 \mu \mathrm{M} \mathrm{CTZ}$ and $2 \mathrm{~mm}$ DGG ( $n=10$ bursts; 1074 events) (Fig. $4 H$ ). We further tested the influence of reducing AMPA receptor occupancy without CTZ present. A lower concentration of DGG (1 mM) was used in the absence of CTZ ( $n=6$ bursts; 680 events) to maintain a high resolution of events (during bursts, mEPSCs were $37 \pm 3 \mathrm{pA}, n=$ 6 in the presence of $1 \mathrm{~mm}$ DGG compared with $79 \pm 10 \mathrm{pA}, n=$ 17 for control). As predicted, mEPSC amplitude was less dependent on $\Delta t$ in the presence of $1 \mathrm{~mm}$ DGG relative to control (Fig. $4 I$ ). Overall, these data indicate that a reduction in receptor occupancy at a single synaptic release site, by preventing desensitization and saturation, can greatly diminish the dependence of mEPSC amplitude on $\Delta t$.

We also examined the effects of glutamate uptake on by re- cording $\alpha$-LTX-triggered bursts of mEPSCs at $35^{\circ} \mathrm{C}$ in the presence of TBOA, a broad spectrum, nontransportable blocker of excitatory amino acid transporters. For bursts collected in the presence of TBOA ( $n=8$ bursts; 525 events), the mEPSC amplitude was not significantly different from control $(90 \pm 16 \mathrm{pA}, n=$ 8 vs $79 \pm 10 \mathrm{pA}, n=17 ; p=0.55)$ and the decay of the mEPSC had a similar time course to control $(\tau=0.7 \mathrm{~ms})$. A burst recorded in the presence of $300 \mu \mathrm{M}$ TBOA is shown along with an aligned plot of mEPSC amplitude versus time (Fig. $4 J$ ). Event amplitude remains constant over time, indicating there is no cumulative desensitization occurring during a sustained bout of release at a single site. The dependence of event amplitude on $\Delta t$ is well approximated by a single exponential with a time constant $\tau=6.8 \pm 0.6 \mathrm{~ms}$ and an amplitude $23 \pm 1 \%$, relative to control bursts $(\tau=4.8 \pm 0.2 \mathrm{~ms}$; amplitude, $32 \pm 1 \%)$. Overall, these results suggest that glutamate uptake does not play an important role in maintaining synaptic responses when single isolated release sites are activated at a high frequency. This result suggests that glutamate diffusion from the synaptic cleft is sufficiently rapid to terminate the glutamate signal and prevent an accumulation of glutamate in the synaptic cleft during sustained activation at a single site.

A summary of the properties of mEPSCs during bursts suggests that desensitization reduces the amplitude of mEPSCs under control conditions when vesicle fusion occurs rapidly at single release sites (Fig. $4 \mathrm{~K}$ ). Under control conditions, both at 24 and $35^{\circ} \mathrm{C}$, the recovery of mEPSC amplitude is markedly slower than the decay of the average mEPSC. When AMPAR desensitization is prevented by CTZ, the time course of mEPSC recovery and of mEPSC decay track one another more closely. Preventing desensitization and saturation with a low affinity antagonist dramatically reduces the dependence of mEPSC amplitude on $\Delta t$. Moreover, for the glutamatergic release sites onto cerebellar stellate cells studied here, the broad spectrum blockade of glutamate transport with TBOA did not dramatically alter the decay of the average $\mathrm{mEPSC}$, or the time constant for the recovery of mEPSC amplitude relative to control conditions.

\section{Synaptically evoked quantal events from single release sites} Our studies of LTX-induced bursts indicate that single release sites are capable of rapid vesicle mobilization and rapid recovery from desensitization. These properties suggest that this synapse can sustain transmission during high-frequency bouts of presynaptic activity. To test this hypothesis, we used a more physiological paradigm by using extracellular stimulation to evoke trains of quantal events from single release sites. These studies required exciting a single granule cell input onto a stellate cell. The low rate of connectivity between granule cells and stellate cells makes paired recording exceedingly difficult. An alternative was to activate cells with minimal extracellular stimulation either with electrodes placed in the granule cell layer, or with electrodes placed in the molecular layer (see Materials and Methods). We took this approach and identified inputs with single release sites using two properties of the $\alpha$-LTX-evoked bursts as criteria for defining the behavior of an individual site. First, the CV for events in a train with $\Delta t$ values $>20$ ms was 0.35 or lower $(0.30 \pm 0.02$ for $\Delta t>20$ $\mathrm{ms} ; n=13$ ). This corresponds to the CV values of isolated events observed for bursts recorded under the same experimental conditions $\left(2 \mathrm{CaCl}_{2}, 35^{\circ} \mathrm{C}\right.$; range, 0.17-0.4; mean $0.29 \pm 0.02 ; n=$ 17). Second, event amplitude was dependent on $\Delta t$, as predicted for a single site and observed for $\alpha$-LTX-evoked bursts (Fig. 3).

High-frequency stimulation evoked a series of responses that were similar to the mEPSC bursts evoked by $\alpha$-LTX. This is 
A

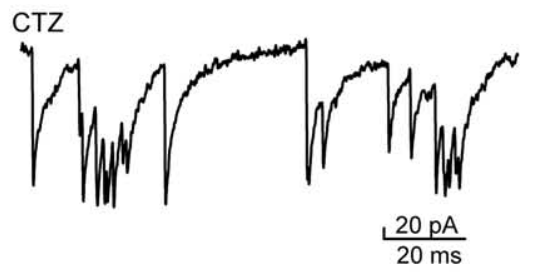

B

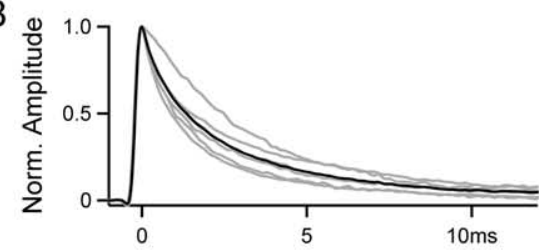

C

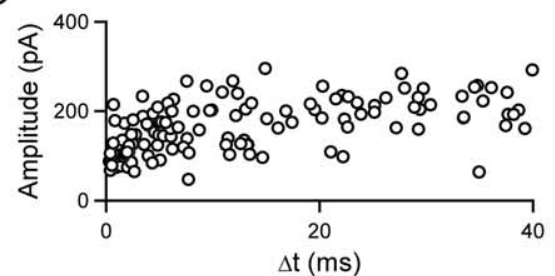

$\mathrm{G}$
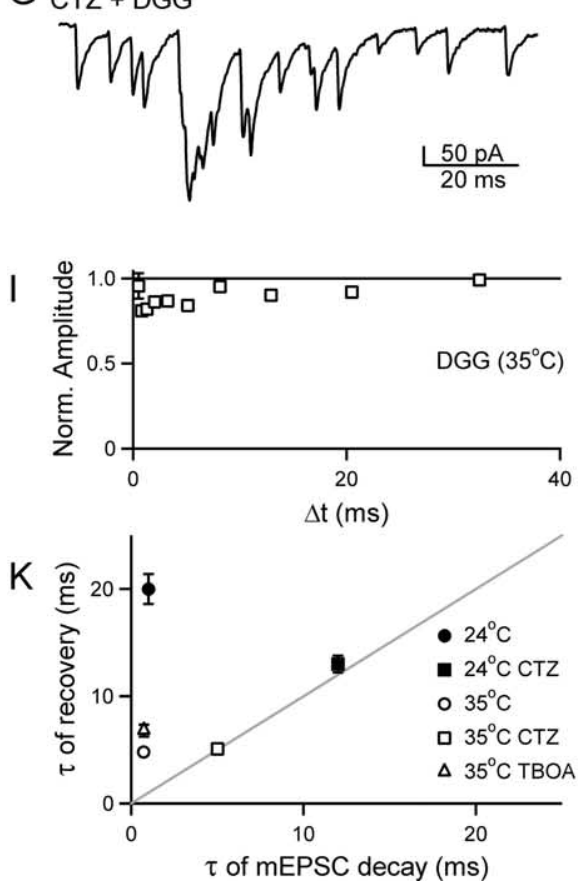
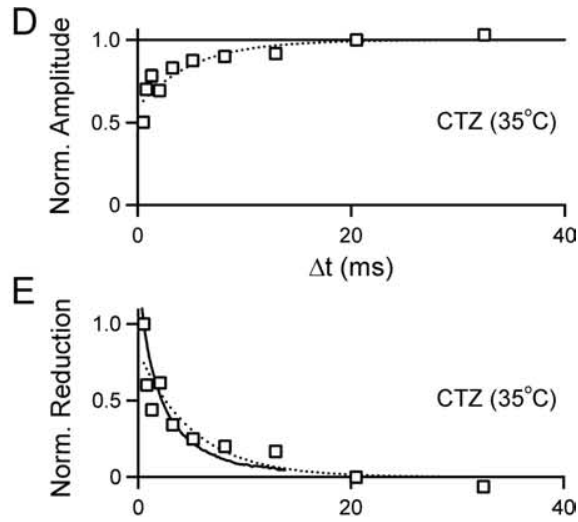

$\mathrm{F}$
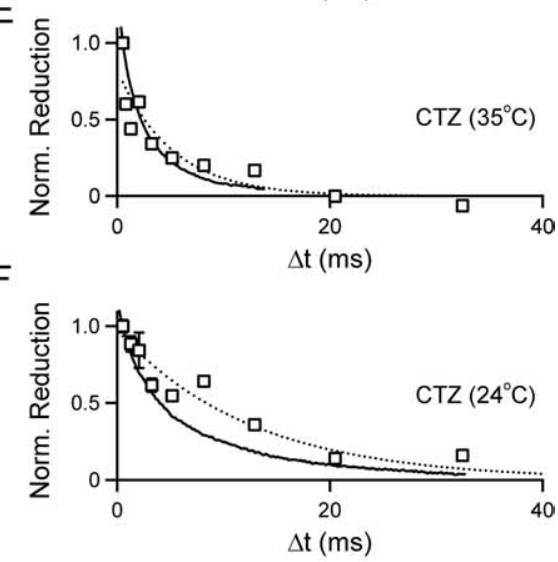

$\mathrm{H}$

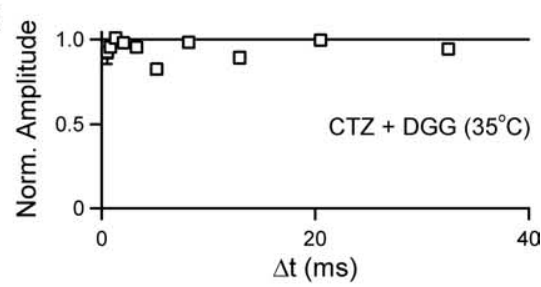

J TBOA
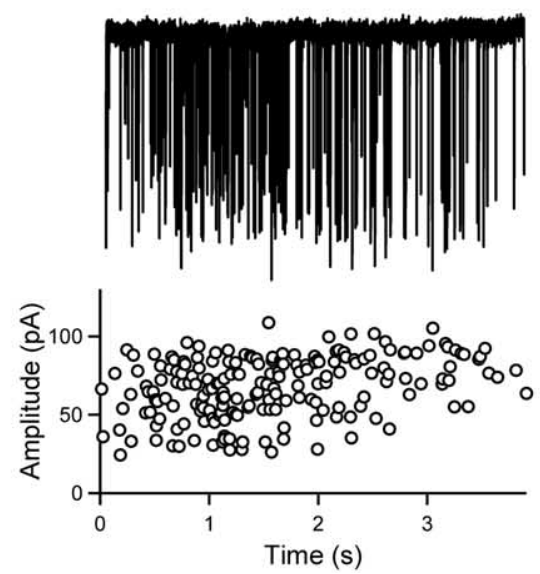

Figure 4. Rapidly recovering AMPAR desensitization underlies the attenuation of mEPSC amplitude at small $\Delta t$ values. $\boldsymbol{A}-\boldsymbol{F}$, $\alpha$-LTX was used to induce bursts in the presence of $100 \mu \mathrm{M}$ (TZ to prevent AMPA receptor desensitization. $\boldsymbol{A}$, A portion of a representative burst in the presence of $\mathrm{CTZ}\left(35^{\circ} \mathrm{C}\right) \cdot \boldsymbol{B}$, Average mEPSCs from six bursts are superimposed (gray lines) and averaged (black line). C, Plot of amplitude versus $\Delta t$ for all events in the burst shown in $A$. $\boldsymbol{D}$, The amplitude versus $\Delta t$ plot across all bursts ( 6 bursts; 600 events, open squares, binned as described in Fig. 3G) was well approximated (dotted line) by the following equation: normalized amplitude $=A \exp (-\Delta t / \tau)$ with fit parameters $[A, \tau(\mathrm{ms})]$ of $[0.37,5.1] . E$, Plot comparing the time course for the reduction in $m E P S C$ amplitude (open boxes, dotted line) with $\Delta t$ to the time course for the decay of the average mEPSC (solid line), as described in Figure $3 H$. The average mEPSC is well approximated by the equation mEPSC decay $=A_{1} \exp \left(-\Delta t / \tau_{1}\right)$ $+A_{2} \exp \left(-\Delta t / \tau_{2}\right)$, with fit parameters $\left[A_{1}, A_{2}, \tau_{1}(\mathrm{~ms}), \tau_{2}(\mathrm{~ms})\right]$ of $[0.54,0.43,1.1,5.0] . \boldsymbol{F}$, Plot comparing the time course for the reduction in $\mathrm{mEPSC}$ amplitude with $\Delta t$ (open boxes, dotted line) to the time course for the decay of the average $\mathrm{mEPSC}$ (solid line) at $24^{\circ} \mathrm{C}$ ( 5 bursts; 507 events). The average mEPSC is well approximated by the equation $\mathrm{mEPSC}$ decay $=A_{1} \exp \left(-\Delta t / \tau_{1}\right)+$ $A_{2} \exp \left(-\Delta t / \tau_{2}\right)$, with fit parameters $\left[A_{1}, A_{2}, \tau_{1}(\mathrm{~ms}), \tau_{2}(\mathrm{~ms})\right]$ of $[0.50,0.49,2.3,12]$. The plot of $\mathrm{mEPSC}$ amplitude versus $\Delta t$ is well approximated (dotted line) by the following equation: normalized amplitude $=A \exp (-\Delta t / \tau)$, with fit parameters $[A, \tau$ (ms)] of $[0.42,13]$. G-I, The dependence of mEPSC amplitude on $\Delta t$ is reduced by decreasing AMPAR occupancy. $\alpha$-LTX-induced bursts were recorded at $35^{\circ} \mathrm{C}$ in the presence of $\mathrm{CTZ}$ and the low-affinity AMPA receptor antagonist DGG to reduce receptor occupancy. $\mathbf{G}$, Time-expanded region of a burst in the presence of $100 \mu \mathrm{M}$ CTZ and $2 \mathrm{~mm}$ DGG. $\boldsymbol{H}$, Summary of amplitude versus $\Delta t$ across all bursts recorded in $100 \mu \mathrm{m}$ (TZ plus 2 mM DGG (10 bursts; 1074 events). I, Summary of amplitude versus $\Delta t$ across all bursts recorded in $1 \mathrm{~mm}$ DGG ( 6 bursts; 680 events). J, Top, representative recording of a burst recorded in the presence of $300 \mu \mathrm{M} \mathrm{TBOA}$.

shown for a train of responses evoked by a regular $100 \mathrm{~Hz}$ stimulation train (Fig. $5 \mathrm{~A}$, top). Poisson trains of $\sim 200 \mathrm{~Hz}$ (minimum ISI $=2.5 \mathrm{~ms}$ ) were interleaved with these regular trains to allow the frequency dependence of transmission to be determined for a range of $\Delta t$ values. Evoked EPSCs consisted of quantal events with rapid rise times. In this example, the $\mathrm{CV}$ of amplitude for events separated by $>20 \mathrm{~ms}$ was 0.26 . In this trial, 87 events were observed over the course of 74 stimuli, with no systematic decrease in event amplitude evident during the train (Fig. $5 \mathrm{~A}$, bottom). This indicates that there is no cumulative desensitization of the AMPARs during the train, suggesting that glutamate spillover and pooling does not occur with this minimal stimulation protocol, in contrast to when greater numbers of parallel fibers are stimulated (Carter and Regehr, 2000). An expanded view of a series of events from the train demonstrates the ability of the release site to follow high-frequency activation, and the occurrence of multiple release events after a single stimulus (Fig. $5 B$ ). A plot of the number of events observed after a stimulus was well approximated by a Poisson distribution with $m=$ $1.07 \pm 0.01$ (Fig. 5C). In this example, there were 0,1 , and multiple events observed 34,36 , and $30 \%$ of the time, compared with 32,39 , and $29 \%$ predicted by a binomial model with $n=8$, corresponding to the number of morphologically docked vesicles at granule cell release sites (Xu-Friedman et al., 2001) and release probability $p_{\mathrm{v}}=(\mathrm{m} / \mathrm{n})=(1.07 / 8)=$ 0.134 . A plot of the time between successive events during the stimulus train showed considerable variation, but showed a trend toward increasing during the train (Fig. 5D). One interpretation of this decrease in the event frequency is that as release-ready vesicles are depleted, the frequency of events later in the train reflects the rate of replenishment from a reserve pool. It could, however, also reflect an inability to sustain reliable highfrequency activation of presynaptic fibers. The poststimulus time histogram com-

$\leftarrow$

Below, the amplitude of each mEPSC is plotted against time on the aligned graph. $\boldsymbol{K}$, Summary of the time constant of recovery of $m E P S C$ amplitude with $\Delta t$ is plotted against the mEPSC decay time constant for bursts under different experimental conditions. In $100 \mu \mathrm{M}$ CTZ, the time constant for singleexponential fits of amplitude versus $\Delta t$ is plotted against $\tau_{2}$ from the double-exponential fits of mEPSC decay. For the control data at $24^{\circ} \mathrm{C}, \tau_{2}$ from the double-exponential fit of amplitude versus $\Delta t$ is plotted against the single-exponential fit of the average $m E P S C$ decay. 
A

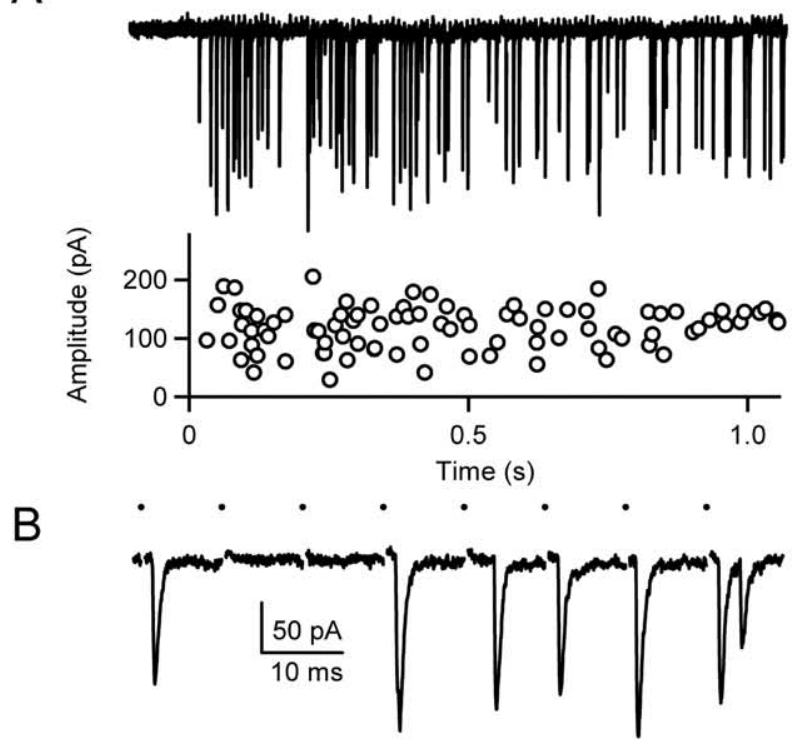

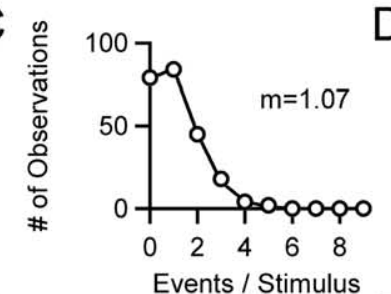

$\mathrm{E}$

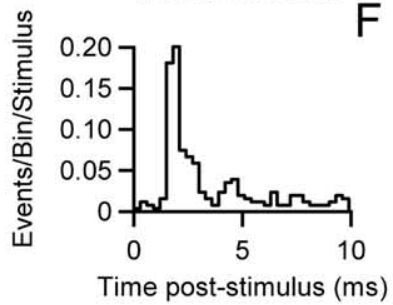

G

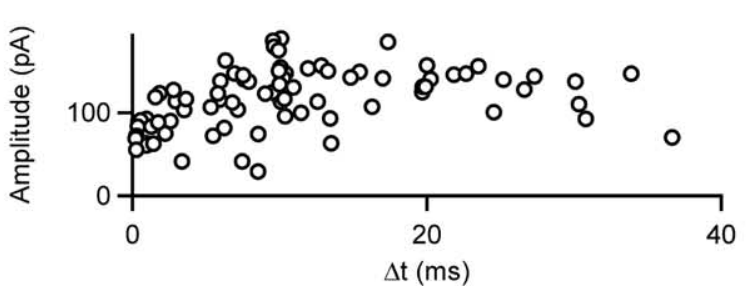

Figure 5. High-frequency trains of quantal events evoked by extracellular stimulation of single synaptic release sites at the granule cell to stellate cell synapse. $A$, Representative recording of AMPAR-mediated quantal events in response to a regular $100 \mathrm{~Hz}$ stimulus train (denoted by dots above the trace). An aligned plot of event amplitude versus time is shown below the trace. $\boldsymbol{B}$, Time-expanded view of a section of the train shown in $\boldsymbol{A}$. $\boldsymbol{C}$, Histogram of the number of events per stimulus compiled for two regular trains from the representative example in $\boldsymbol{A}$ (open circles), along with a fit of the data using a Poisson function (solid line; $m=1.07$ ). $\boldsymbol{D}$, Plot of $\Delta t$ versus event number for the train shown in $\boldsymbol{A}$ (open circles), along with the running average (10 point) (filled circles). $\boldsymbol{E}$, Poststimulus time histogram for two regular $100 \mathrm{~Hz}$ trains from the site shown in $\boldsymbol{A}$. $\boldsymbol{F}$, Cumulative histogram exhibiting a shift toward smaller amplitudes for events that occur with a short $\Delta t(<3 \mathrm{~ms}$ ) relative to events with longer latencies ( $>10$ $\mathrm{ms}$ ), compiled for three trains (regular and Poisson) of events from the cell shown in A. G, Plot of amplitude versus $\Delta t$ for the representative train shown in $A$, exhibiting a reduction in amplitude at small values of $\Delta t$ consistent with the behavior of a single synaptic release site.

piled for regular trains from this release site revealed that the majority of events were locked to the stimulus with latencies of $\sim 2$ ms (Fig. $5 E$ ). A cumulative histogram of event amplitudes compiled for three trains from the same cell showed that events with a $\Delta t$ of $3 \mathrm{~ms}$ or less were smaller than events separated by $>10 \mathrm{~ms}$ (Fig. $5 F$ ). The time dependence of event amplitude was also apparent in the plot of the amplitude versus $\Delta t$ of the events from the representative train (Fig. $5 G$ ).

A summary of 13 experiments revealed that the evoked EPSCs were reduced by $38 \pm 2 \%$ immediately after another event, and that the time dependence of this decrease recovered with a time constant of $5.4 \pm 0.9 \mathrm{~ms}$ (Fig. $6 \mathrm{~A}$, dotted line). These properties are similar to the properties of mEPSCs during bursts ( $32 \pm 1 \%$ reduction and a recovery time constant of $4.8 \pm 0.2 \mathrm{~ms}$ ). The fits for each individual experiment demonstrate the variation across individual release sites in the extent and recovery from desensitization observed (Fig. $6 \mathrm{~B}$, gray lines). The initial reduction ranged from $29 \pm 4 \%$ to $51 \pm 7 \%$, and the time constants of recovery ranged from $1.4 \pm 0.5 \mathrm{~ms}$ (open circles, black line) to $15 \pm 4.9 \mathrm{~ms}$ (Fig. $6 B$, closed circles, black line). There was no significant correlation between the extent of desensitization and recovery from desensitization in these experiments $(n=13)$ (Fig. 6C). Overall, this suggests that there is site-to-site variability in the timingdependent decrease in event amplitude.

\section{Distinguishing between one site and two sites using simulations}

Whether the quantal events observed during a train arise from a single site or multiple sites is crucial to the interpretation of our observations. It is highly unlikely that the fusion of a single vesicle at one site could consistently lead to desensitization at neighboring sites for synapses on stellate cells; therefore, the prominent desensitization we observed $(0.38 \pm 0.03 ; n=13)$ suggests that at most two sites could be contributing to the events evoked by a train. Is it possible that the events evoked during trains arise from two sites that give rise to the frequency dependence of EPSC amplitude we observed? We examined this possibility by performing simulations in which it was assumed that the events during a train were produced by either a single site or by two sites. These simulations were based on experimentally determined distributions of quantal sizes for large $\Delta t$ values, the timing of events relative to stimulation, and the observed properties of desensitization. Such a simulation is shown for the experiment in Figure 5. As shown in Figure 7A, for the fusion of two vesicles at a single site, desensitization decreases the amplitude of the second event. If the events arise from two independent sites, two distinct cases occur. When vesicle fusion at one site is followed by vesicle fusion at a second site, desensitization will not attenuate the amplitude of the second quantal event (Fig. $7 B$, left). If both vesicles fuse at the same site then the amplitude of the second event will be greatly attenuated by desensitization (Fig. $7 B$, right). In order for the two-site case to give the observed average desensitization as a function of $\Delta t$, the extent of desensitization must be twice as large as for a single site because only half of the closely spaced events will be affected.

We first considered the case in which event amplitude was determined exclusively by the timing of events and there was no stochastic variability in the amplitude of the events. For a train delivered to a single site, the normalized amplitudes all conformed to the observed extent and recovery of desensitization as a function of $\Delta t$ (Fig. 7C). For two independent sites, the amplitudes of events at a given site were determined by the $\Delta t$ for events occurring at that site, and were independent of events occurring at the second site. Approximately half of the events showed little or no desensitization, and half showed a large extent of desensitization (Fig. 7D). Thus, in the absence of stochastic variability, the one-site and two-site cases are readily distinguished. 
The inclusion of the observed stochastic variation in the amplitudes of the quantal events profoundly affects the relationship between amplitude and $\Delta t$ for both the one-site (Fig. 7C, lower) and two-site (Fig. 7D, lower) cases. In this example, the amplitude of the responses varied with the $\mathrm{CV}$ of 0.26 that was observed in the experiment shown in Figure 5. Even with stochastic variation, a comparison of the amplitude histograms and cumulative amplitude histograms for the one-site (Fig. 7E) and two-site cases (Fig. 7F) revealed significant differences between the two regarding the $\mathrm{CV}$ for events at $\Delta t_{1}>20$ ms (Fig. $7 E, F$, black traces) and $\Delta t_{2}=0-1$ $\mathrm{ms}$ (Fig. $7 E, F$, gray traces). In this example simulation for a single site, the CV was approximately the same for $\Delta t_{1}$ and $\Delta t_{2}, 0.25$ and 0.26 , respectively. For two sites, the CV rose from 0.25 for $\Delta t_{1}$ to 0.56 for $\Delta t_{2}$ because a significant fraction of the events occurring in the range of $\Delta t_{2}$ were unaffected by desensitization leading to a larger variability in event amplitude. These simulations were repeated for each experiment $(n=13)$ using the CV values for $\Delta t_{1}$ and the properties of desensitization observed for each one. For a one-site model, the CVs were the same for $\Delta t_{1}$ and $\Delta t_{2}(0.31 \pm 0.02$ and $0.32 \pm 0.02$, respectively) (Fig. 7G, left). For a two-site model, the CVs increased from $0.31 \pm 0.02$ to $0.51 \pm 0.05$ for $\Delta t_{1}$ and $\Delta t_{2}$, respectively (Fig. 7G, right). Thus, a comparison of the CVs of the amplitude distributions for widely spaced and closely spaced events can be used to discriminate between one-site and two-site models.

We therefore examined the amplitude distributions for $\Delta t_{1}$ and $\Delta t_{2}$ for each experiment $(n=13)$ similar to the one shown in Figure 5. For these experiments, the $\mathrm{CV}$ was virtually unchanged for $\Delta t_{1}$ and $\Delta t_{2}(0.30 \pm 0.02$ and $0.33 \pm 0.01$, respectively) (Fig. $7 H)$. These findings suggest that the quantal events observed during a train arise from vesicle fusion at a single site. They are incompatible with the large increase in CV expected for closely spaced events if two sites were involved.

\section{Reductions in AMPAR occupancy reduce the dependence of EPSC amplitude on $\Delta t$}

If single release sites mediate the events in these evoked trains, preventing desensitization and saturation by reducing AMPAR occupancy with the low-affinity antagonist DGG should minimize the reduction in EPSC amplitude at short latency, as was observed for $\alpha$-LTX-evoked bursts (Fig. $4 H, I$ ). In contrast, the frequency dependence of event amplitude should persist after wash-in of the high-affinity antagonist NBQX. We next performed wash-in experiments with these AMPAR antagonists to assess their effects on trains of evoked EPSCs from single release sites. Control responses compiled for three sites in which DGG (1-2 mM) was subsequently applied exhibited a time-dependent decrease in event amplitude for closely spaced events, with a time constant of $5.7 \pm 0.6 \mathrm{~ms}$, and an amplitude of $46 \pm 1 \%$ (Fig. $8 \mathrm{~A}$, open circles, dotted line). After the wash-in of DGG, the timedependent decrease in event amplitude for closely spaced events was much less pronounced $(15 \pm 5 \%$ and a time constant of $4.4 \pm 4.4 \mathrm{~ms}$ ) (Fig. 8A, filled squares, solid line). On average, DGG reduced the event amplitude to $35 \pm 11 \%$ of control. Figure $8 B$ plots the amplitude of short latency mEPSCs $(\Delta t<3 \mathrm{~ms})$,
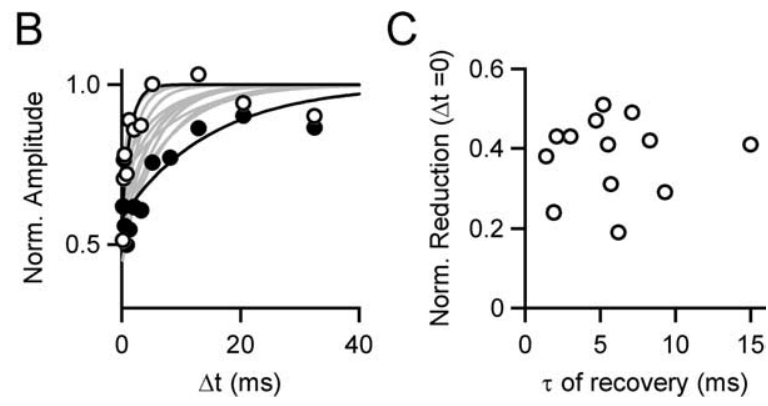$$
15
$$

Figure 6. Variation in the extent and recovery from desensitization at single release sites. $A$, Summary of amplitude versus $\Delta t$ for trains of events evoked by extracellular stimulation. A plot of amplitude versus $\Delta t$ is shown for the average of 13 sites (open ircles). The amplitude versus $\Delta t$ plot, normalized and binned as described in Figure $2 G$, was well approximated by the equation and slowe (fille

normalized to the amplitude for well separated events $(\Delta t>20$ $\mathrm{ms}$ ), for control conditions and in the presence of DGG. At each individual site (open circles with lines), and for the average of the three sites (filled circles with line), DGG prevents the reduction in event amplitude for short-latency events. These data are consistent with a single population of AMPARs mediating the evoked EPSCs in the train, and that minimizing desensitization with a fastoff antagonist can decrease the frequency-dependent reduction in event amplitude. In contrast, the high-affinity antagonist NBQX did not affect the extent ( $47 \pm 4$ vs $38 \pm 3 \%$ for control) of the decrease in amplitude for closely spaced events (Fig. $8 C, D)(n=3)$, despite reducing the event amplitude to a similar extent (48 $\pm 7 \%$ ).

Thus, the properties of EPSCs evoked by high-frequency stimulation from single synaptic release sites confirm and extend our results obtained with $\alpha$-LTX-evoked bursts. The recovery from desensitization is fast, with a time constant of $5 \mathrm{~ms}$ at $35^{\circ} \mathrm{C}$. In addition, it is clear that single sites can rapidly mobilize large numbers of vesicles in response to high-frequency stimulation. In all cases, the number of events observed after a stimulus was well approximated by Poisson distributions with $m=0.60 \pm 0.26$ ( $\pm \mathrm{SD} ; n=13$ ). As for the $\alpha$-LTX-evoked bursts, tens to hundreds of vesicles are mobilized at frequencies of tens to hundreds of Hertz. The average event latency during the course of a stimulation train (Fig. 9A) remains constant for $\sim 40$ events, and increases modestly as the train progresses. The average latency over the first 40 events is $13 \mathrm{~ms}$ ( $n=31-56$ trains), which increases to 29 ms between 60 and 80 events ( $n=12-24$ trains). In contrast, $\alpha$-LTX bursts at the same temperature have an average latency of $25 \mathrm{~ms}$ over the first 40 events ( $n=39-45$ bursts), which remains fairly constant at $28 \mathrm{~ms}$ between 60 and 80 events ( $n=23-27$ bursts). It is particularly important that evoked trains of presynaptic activity can mobilize vesicles at the rates observed for $\alpha$-LTX bursts and higher, given the observation that different populations of vesicles may underlie spontaneous versus evoked synaptic transmission (Sara et al., 2005). This is apparent in a plot of the average EPSC frequency versus the total number of events evoked by trains (Fig. 9B). The average event frequency during trains from 13 individual sites was $63 \pm 7 \mathrm{~Hz}$, providing an estimate of $\sim 15 \mathrm{~ms}$ for vesicle replenishment. Together, our data indicate that single release sites at the granule cell to stellate cell synapse are well suited to sustain synaptic transmission at high frequency through a combination of rapid vesicle replenishment (15-20 ms), and fast recovery from desensitization $(\tau=5 \mathrm{~ms})$. 


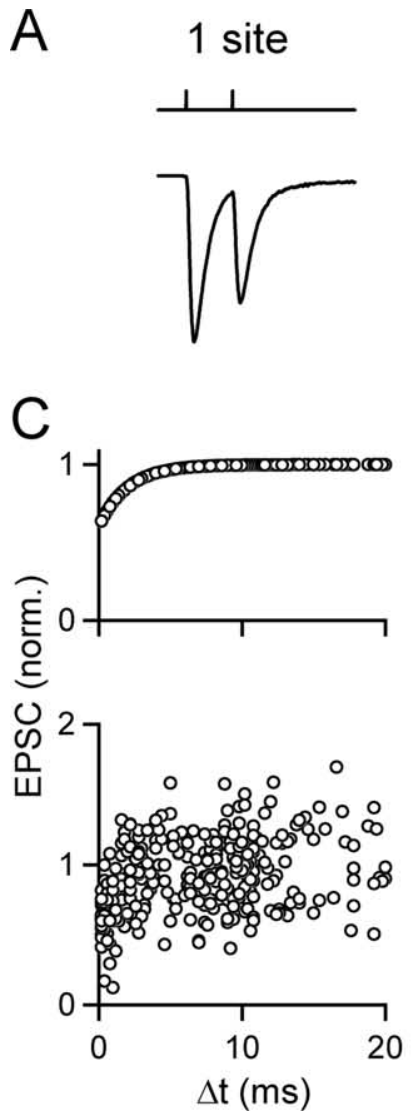

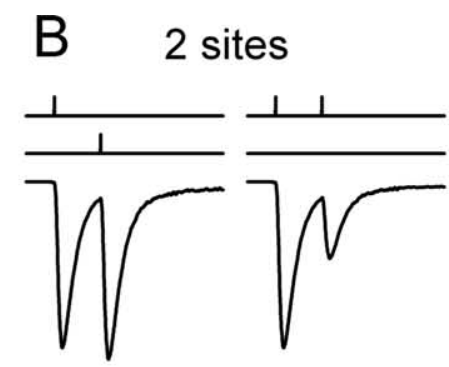

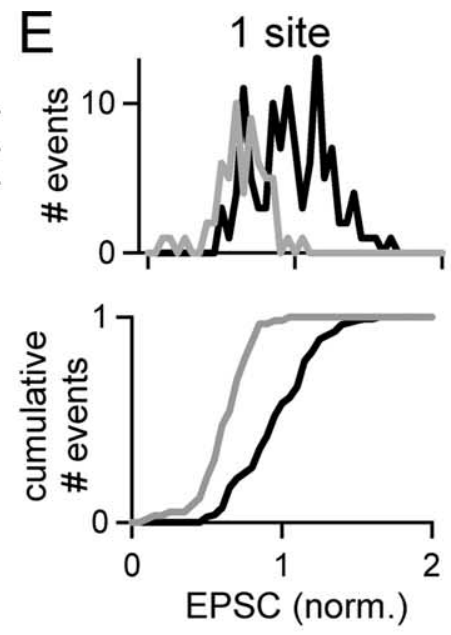

G Simulations
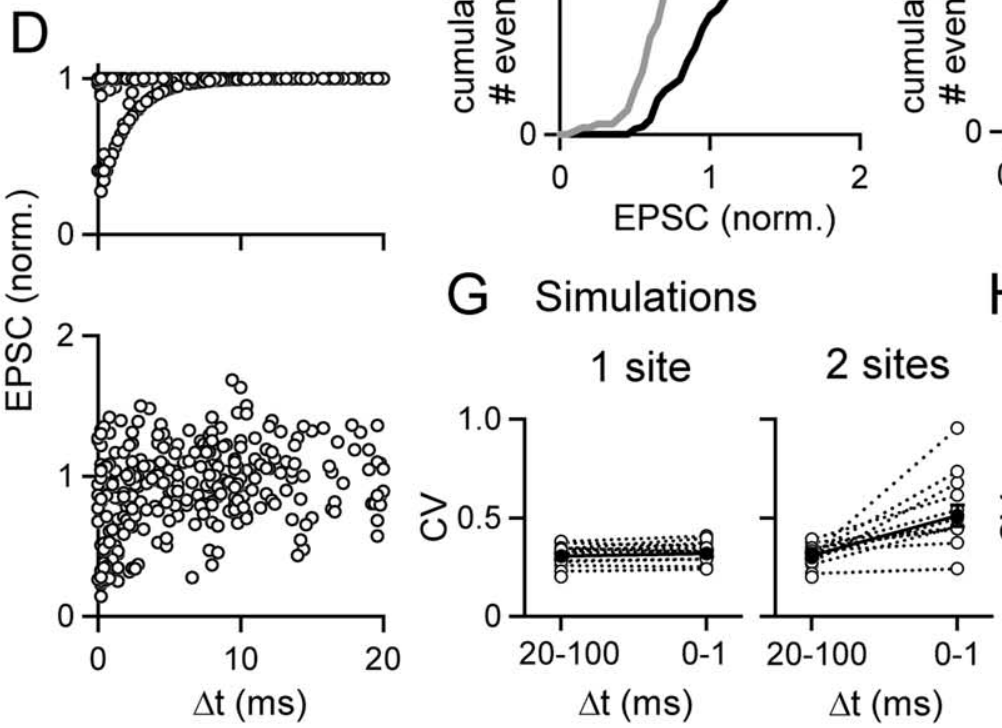

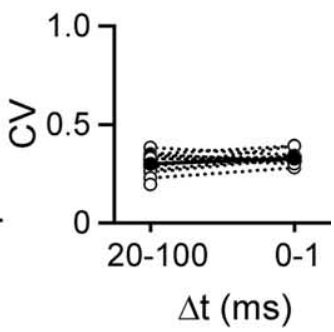

Figure 7. $\boldsymbol{A}-\boldsymbol{F}$, Simulations of quantal responses during trains are shown for events arising from a single site $(\boldsymbol{A}, \boldsymbol{C}, \boldsymbol{E})$ or from two sites $(\boldsymbol{B}, \boldsymbol{D}, \boldsymbol{F})$. Example responses are shown with the timing of vesicle fusion shown above and the resulting currents shown below for a single site $(\boldsymbol{A})$ and for two sites $(\boldsymbol{B})$. $\boldsymbol{B}$, If two sites are present no desensitization occurs if the quantal events reflect fusion at different sites (left), but significant desensitization occurs if two vesicles fuse in rapid succession at the same site (right). Simulations were conducted based on the measured probability of observing a quantal event at any time during the train, and on the observed dependence of event amplitude on the $\Delta t$ value. In this example, there were a total of 300 stimuli at $100 \mathrm{~Hz}$. ( $\boldsymbol{C}$, top) For a single site, the amplitude is given by EPSC $=\operatorname{EPSC}_{0}(1-0.4 \exp (-\Delta t / \tau))$, where $\Delta t$ is the time between the given fusion and the preceding vesicle fusion. $D$, Top, For two sites, EPSC $=$ $\operatorname{EPSC}_{0}(1-0.8 \exp (-\Delta t / \tau))$, where $\Delta t$ is the time between the given fusion and the preceding vesicle fusion at that same site. $C, D, B o t t o m$, The variability of EPSC amplitude was included by determining EPSC amplitude stochastically using the observed coefficient of variation for widely spaced events ( $\Delta t>20 \mathrm{~ms}$ ) that are unaffected by desensitization. The amplitude distributions for events arising from a single site ( $\boldsymbol{E}$, top) and two sites $(\boldsymbol{F}$, top) are shown for $\Delta t=0-1 \mathrm{~ms}$ (gray) and $\Delta t=10-60 \mathrm{~ms}$ (black), along with the normalized cumulative histograms for a single site $(\boldsymbol{E}$, bottom) and two sites $(\boldsymbol{F}$, bottom). $\boldsymbol{G}$, The predicted $C V$ values are $\Delta t=20-100 \mathrm{~ms}$ and $\Delta t=0-1 \mathrm{~ms}$ for the single site and two site cases, respectively. $\boldsymbol{H}$, The observed CV values conform to the prediction for a single site.

\section{Discussion}

Here, we find that single glutamatergic release sites at the cerebellar granule cell to stellate cell synapse can sustain synaptic transmission at remarkably high frequencies. Presynaptically, vesicles can be mobilized at rates approaching 100 vesicles per second at single release sites. Postsynaptically, AMPA receptor desensitization recovers within several milliseconds. Together, these presynaptic and postsynaptic properties interact to allow granule cells to maintain synaptic transmission even during prolonged presynaptic activity patterns.

\section{Vesicle mobilization at single release sites}

The observation that single granule cell to stellate cell synapses can release vesicles at high rates provides insight into the process of vesicle mobilization, which is a limiting factor in maintaining synaptic efficacy during sustained activity. Because only a small fraction of vesicles are docked at the membrane and competent for immediate release after action potential invasion, vesicles must be transferred from a reserve pool to the release-ready pool. During high-frequency stimulation, vesicles can be released at higher rates than they can be mobilized from reserve pools, leading to depletion and synaptic depression (von Gersdorff and
Matthews, 1997; Schneggenburger et al., 2002; Zucker and Regehr, 2002; Foster and Regehr, 2004; Singer and Diamond, 2006). At granule cell synapses, there are $\sim 500$ total vesicles associated with individual release sites, of which only seven to eight are morphologically docked (Xu-Friedman et al., 2001). Therefore, whether evoked by $\alpha$-LTX or extracellular stimulation, bursts of events consisting of many tens to hundreds of events over several seconds must involve the mobilization of vesicles from a reserve pool (Figs. 2E, 9B). This is consistent with ultrastructural studies at the frog neuromuscular junction demonstrating that the presynaptic terminal is thoroughly depleted of reserve pool vesicles after $\alpha$-LTX treatment (Ceccarelli et al., 1979). The average event frequency during a train or burst provides a means of estimating the time taken to mobilize vesicles from a reserve to the releaseready pool. In our experiments, the average frequency across bursts and evoked trains ( $100 \mathrm{~Hz}$ regular and $\sim 200 \mathrm{~Hz}$ Poisson) at $35^{\circ} \mathrm{C}$ was $47 \pm 5 \mathrm{~Hz}(n=48)$ and $63 \pm 7 \mathrm{~Hz}(n=13)$, respectively. In some bursts, the frequency approached 200 events/s. This corresponds to an average of 15-20 ms for mobilization of vesicles from reserve to release ready pools, and just $5 \mathrm{~ms}$ at some release sites. The rapid rate of mobilization we observed at granule cell to stellate cell synapses is consistent with the ability of 
these synapses to transmit information during sustained high-frequency firing.

There is considerable diversity in the ability of different central synapses to mobilize vesicles. Many central synapses are much less effective than granule cells at maintaining synaptic efficacy during with high-frequency activity. At the climbing fiber to Purkinje cell synapse, a single stimulus can deplete release-ready vesicles and give rise to prominent synaptic depression (Foster and Regehr, 2004). Vesicle replenishment occurs with fast and slow components of $\sim 100 \mathrm{~ms}$ and $3 \mathrm{~s}$, respectively (Dittman and Regehr, 1998; Foster et al., 2002). This rate of vesicle replenishment is, however, adequate for the climbing fiber synapse, which generally fires at 1-2 $\mathrm{Hz}$ in vivo (Thach, 1968). At some synapses where the presynaptic cell fires rapidly, such as the calyx of Held (500-800 $\mathrm{Hz}$ ) (Guinan and Li, 1990; Spirou et al., 1990; Smith et al., 1998), fast exocytosis of the readily releasable pool and slow vesicle mobilization $\left(\tau_{1} \sim 200 \mathrm{~ms} ; \tau_{2} \sim 4.5 \mathrm{~s}\right)$ (Sakaba and Neher, 2001, 2003; Sun and $\mathrm{Wu}, 2001)$ result in depletion that limits synaptic efficacy during high-frequency firing (Schneggenburger et al., 2002). However, although it takes seconds to recover from depletion, the calyx of Held is comprised of hundreds of release sites, and a small fraction of these with release-ready vesicles can produce a large postsynaptic response (von Gersdorff and Borst, 2002). In contrast, the high rate of vesicle mobilization we observed at the granule cell to stellate cell synapse is reminiscent of the cerebellar mossy fiber to granule cell synapse, where it takes 12-50 ms to translocate, dock, and prime a vesicle (Saviane and Silver, 2006). Because granule cells and mossy fibers can both fire at high frequency for sustained periods (van Kan et al., 1993; Jorntell and Ekerot, 2006) and contact their targets with a small number of release sites, rapid vesicle mobilization is essential for these synapses to transmit information during prolonged bouts of high-frequency transmission. Thus, the diverse ability of different types of synapses to mobilize vesicles appears to be consistent with the functional roles of the synapses in vivo.

\section{Contribution of AMPAR desensitization to synaptic transmission}

AMPAR desensitization does not significantly influence transmission at the granule cell to stellate cell synapse until the presynaptic firing rate surpasses $100 \mathrm{~Hz}$. This can be explained in part by the small initial extent of desensitization caused by a single vesicle $(\sim 35 \%)$, and by a very rapid recovery from desensitization $(\sim 5 \mathrm{~ms})$. The primary determinants of the extent and recovery from desensitization are the glutamate signal and receptor composition.

Previous studies suggest that the glutamate signal at stellate cell synapses is short lived, and likely reflects rapid diffusion away from the release site (Barbour et al., 1994). Our observation that the broad spectrum glutamate uptake inhibitor TBOA does not significantly alter the postsynaptic responses at a single site during a burst at the granule cell-stellate cell synapse is consistent with the rapid diffusion of glutamate from the synaptic cleft terminating the glutamate signal. Such a rapid glutamate signal is
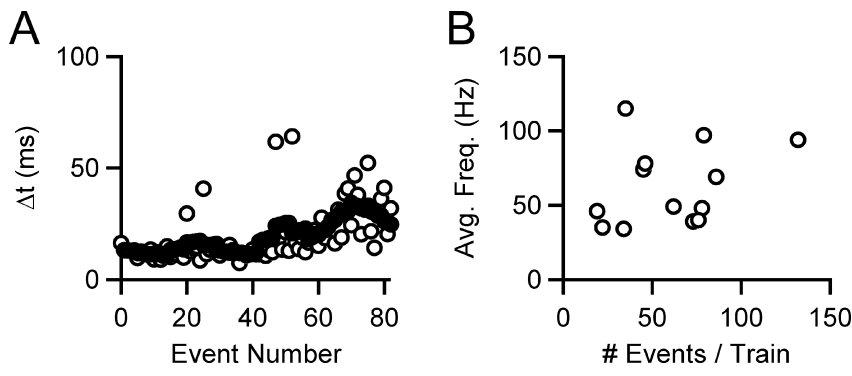

Figure 9. Single release sites rapidly mobilize vesicles for release in response to trains of extracellular stimuli. $A$, A plot of the $\Delta t$ versus event number averaged across 13 individual release sites (open circles), along with the running average (10 point, filled circles). $\boldsymbol{B}$, A plot of the average frequency of events in a train (defined as the number of events divided by the duration between first and last event) against the number of events in the mEPSC train demonstrates that parallel fiber boutons can release tens to hundreds of vesicles (average, 61 events), at frequencies of tens to hundreds of Hertz (average, $63 \mathrm{~Hz}$ ).

quite different from synapses where desensitization is prominent, which usually have multiple closely spaced release sites and lack extensive glial ensheathment between sites (Satzler et al., 2002; Xu-Friedman and Regehr, 2003, 2004). This ultrastructural arrangement, combined with a high initial probability of release, can lead to glutamate spillover and pooling, which prolongs the glutamate signal and promotes AMPAR desensitization (Trussell et al., 1993; Rozov et al., 2001; Chen et al., 2002; DiGregorio et al., 2002; Xu-Friedman and Regehr, 2003, 2004; Nielsen et al., 2004). The rapid recovery from desensitization we observed at the granule cell to stellate cell synapse $\left(\tau \approx 5 \mathrm{~ms} ; 35^{\circ} \mathrm{C}\right)$ is faster than that reported for the time constants of recovery from desensitization after the application of glutamate pulses to excised patches containing AMPARs from hippocampal CA3/CA1 neurons [50-60 ms; room temperature (RT)] (Colquhoun et al., 1992), Purkinje cells $\left(17 \mathrm{~ms} ; 32-35^{\circ} \mathrm{C}\right)$ (Wadiche and Jahr, 2001), rat caudateputamen neurons (100-300 ms; RT) (Jahn et al., 1998), chick nucleus magnocellularis neurons (19 ms; RT) (Trussell et al., 
1993), and catfish cone cells (8.7 ms; RT) (Eliasof and Jahr, 1997). An explanation for the speed of recovery we observed is that low occupancy results in rapid recovery from desensitization (Robert and Howe, 2003). Because the glutamate signal after vesicle fusion decays within tens of microseconds, it is difficult to mimic with rapid glutamate application (Clements et al., 1992; Tong and Jahr, 1994; Clements, 1996; Diamond and Jahr, 1997). As a result, the occupancy of AMPARs could be higher after artificial glutamate application than after the fusion of a single vesicle. Thus, relatively low occupancy after fusion of a vesicle is likely an important factor in the remarkably rapid recovery from desensitization we observed at the granule cell to stellate cell synapse.

The properties of glutamate-induced desensitization of AMPARs also depend on the subunit composition and the association with auxiliary proteins present at the synapse. Flip splice variants tend to be more resistant to desensitization and recover more rapidly from desensitization than flop splice variants (Sommer et al., 1990; Mosbascher et al., 1994; Partin et al., 1994). Studies of mRNA distribution (Keinanen et al., 1990; Sato et al., 1993), AMPAR rectification (Liu and Cull-Candy, 2000, 2002), and sensitivity to cyclothiazide (Partin et al., 1994; Liu and CullCandy, 2000, 2002) (Fig. 4) suggest that a significant portion of the AMPARs in stellate cells contain the flip splice variant and that the predominant AMPARs are GluR2/3 heteromers and GluR3 homomers. In excised patches, recombinant receptors composed of these subunits and splice variants recover from desensitization in 50-130 ms (Schlesinger et al., 2005). Although this is slower than the recovery from desensitization we observed at this synapse, these experiments were performed at room temperature and desensitization was produced by large, prolonged glutamate signals that promote high receptor occupancy, maximal desensitization, and a correspondingly slow recovery. Furthermore, auxiliary proteins such as stargazin (Nicoll et al., 2006), which reduces the extent and speeds the recovery from desensitization (Priel et al., 2005; Turetsky et al., 2005), could contribute to the more rapid recovery from desensitization that we observed in the slice relative to these studies of recombinant receptors.

\section{Summary}

Despite the fact that granule cells often contact stellate cells via a single release site, they are capable of influencing stellate cell firing even during sustained presynaptic activity. This is accomplished through rapid vesicle mobilization that prevents vesicle depletion, through rapid recovery from desensitization of AMPA receptors, which maintains the postsynaptic sensitivity, and by having the fusion of just a single vesicle evoke a large response in stellate cell activity.

\section{References}

Arai A, Lynch G (1998) AMPA receptor desensitization modulates synaptic responses induced by repetitive afferent stimulation in hippocampal slices. Brain Res 799:235-242.

Atluri PP, Regehr WG (1998) Delayed release of neurotransmitter from cerebellar granule cells. J Neurosci 18:8214-8227.

Auger C, Marty A (1997) Heterogeneity of functional synaptic parameters among single release sites. Neuron 19:139-150.

Augustin I, Rosenmund C, Sudhof TC, Brose N (1999) Munc13-1 is essential for fusion competence of glutamatergic synaptic vesicles. Nature 400:457-461.

Barbour B, Keller BU, Llano I, Marty A (1994) Prolonged presence of glutamate during excitatory synaptic transmission to cerebellar Purkinje cells. Neuron 12:1331-1343.

Bekkers JM, Stevens CF (1995) Quantal analysis of EPSCs recorded from small numbers of synapses in hippocampal cultures. J Neurophysiol 73:1145-1156.

Capogna M, McKinney RA, O'Connor V, Gahwiler BH, Thompson SM (1997) $\mathrm{Ca}^{2+}$ or $\mathrm{Sr}^{2+}$ partially rescues synaptic transmission in hippocampal cultures treated with botulinum toxin $\mathrm{A}$ and $\mathrm{C}$, but not tetanus toxin. J Neurosci 17:7190-7202.

Carter AG, Regehr WG (2000) Prolonged synaptic currents and glutamate spillover at the parallel fiber to stellate cell synapse. J Neurosci 20:4423-4434.

Carter AG, Regehr WG (2002) Quantal events shape cerebellar interneuron firing. Nat Neurosci 5:1309-1318.

Ceccarelli B, Grohovaz F, Hurlbut WP (1979) Freeze-fracture studies of frog neuromuscular junctions during intense release of neurotransmitter. I. Effects of black widow spider venom and $\mathrm{Ca}^{2+}$-free solutions on the structure of the active zone. J Cell Biol 81:163-177.

Chadderton P, Margrie TW, Hausser M (2004) Integration of quanta in cerebellar granule cells during sensory processing. Nature 428:856-860.

Chen C, Blitz DM, Regehr WG (2002) Contributions of receptor desensitization and saturation to plasticity at the retinogeniculate synapse. Neuron 33:779-788.

Clements JD (1996) Transmitter timecourse in the synaptic cleft: its role in central synaptic function. Trends Neurosci 19:163-171.

Clements JD, Lester RA, Tong G, Jahr CE, Westbrook GL (1992) The time course of glutamate in the synaptic cleft. Science 258:1498-1501.

Colquhoun D, Jonas P, Sakmann B (1992) Action of brief pulses of glutamate on AMPA/kainate receptors in patches from different neurones of rat hippocampal slices. J Physiol (Lond) 458:261-287.

Debanne D, Guerineau NC, Gahwiler BH, Thompson SM (1996) Paired-pulse facilitation and depression at unitary synapses in rat hippocampus: quantal fluctuation affects subsequent release. J Physiol (Lond) 491:163-176.

Diamond JS, Jahr CE (1997) Transporters buffer synaptically released glutamate on a submillisecond time scale. J Neurosci 17:4672-4687.

DiGregorio D, Nusser Z, Silver R (2002) Spillover of glutamate onto synaptic AMPA receptors enhances fast transmission at a cerebellar synapse. Neuron 35:521-533.

Dingledine R, Borges K, Bowie D, Traynelis SF (1999) The glutamate receptor ion channels. Pharmacol Rev 51:7-61.

Dittman JS, Regehr WG (1998) Calcium dependence and recovery kinetics of presynaptic depression at the climbing fiber to Purkinje cell synapse. J Neurosci 18:6147-6162.

Eliasof S, Jahr CE (1997) Rapid AMPA receptor desensitization in catfish cone horizontal cells. Vis Neurosci 14:13-18.

Forti L, Bossi M, Bergamaschi A, Villa A, Malgaroli A (1997) Loose-patch recordings of single quanta at individual hippocampal synapses. Nature 388:874-878

Foster KA, Regehr WG (2004) Variance-mean analysis in the presence of a rapid antagonist indicates vesicle depletion underlies depression at the climbing fiber synapse. Neuron 43:119-131.

Foster KA, Kreitzer AC, Regehr WG (2002) Interaction of postsynaptic receptor saturation with presynaptic mechanisms produces a reliable synapse. Neuron 36:1115-1126.

Griesinger CB, Richards CD, Ashmore JF (2005) Fast vesicle replenishment allows indefatigable signalling at the first auditory synapse. Nature 435:212-215.

Guinan Jr JJ, Li RY (1990) Signal processing in brainstem auditory neurons which receive giant endings (calyces of Held) in the medial nucleus of the trapezoid body of the cat. Hear Res 49:321-334.

Hashimoto K, Kano M (1998) Presynaptic origin of paired-pulse depression at climbing fibre-Purkinje cell synapses in the rat cerebellum. J Physiol (Lond) 506:391-405.

Hjelmstad GO, Isaac JT, Nicoll RA, Malenka RC (1999) Lack of AMPA receptor desensitization during basal synaptic transmission in the hippocampal slice. J Neurophysiol 81:3096-3099.

Isaacson JS, Walmsley B (1996) Amplitude and time course of spontaneous and evoked excitatory postsynaptic currents in bushy cells of the anteroventral cochlear nucleus. J Neurophysiol 76:1566-1571.

Jahn K, Bufler J, Franke C (1998) Kinetics of AMPA-type glutamate receptor channels in rat caudate-putamen neurones show a wide range of desensitization but distinct recovery characteristics. Eur J Neurosci 10:664-672.

Jorntell H, Ekerot CF (2006) Properties of somatosensory synaptic integration in cerebellar granule cells in vivo. J Neurosci 26:11786-11797. 
Keinanen K, Wisden W, Sommer B, Werner P, Herb A, Verdoorn TA, Sakmann B, Seeburg PH (1990) A family of AMPA-selective glutamate receptors. Science 249:556-560.

Khvotchev M, Lonart G, Sudhof TC (2000) Role of calcium in neurotransmitter release evoked by alpha-latrotoxin or hypertonic sucrose. Neuroscience 101:793-802.

Kuromi H, Kidokoro Y (2005) Exocytosis and endocytosis of synaptic vesicles and functional roles of vesicle pools: lessons from the Drosophila neuromuscular junction. Neuroscientist 11:138-147.

Liu G, Tsien RW (1995) Properties of synaptic transmission at single hippocampal synaptic boutons. Nature 375:404-408.

Liu SJ, Cull-Candy SG (2002) Activity-dependent change in AMPA receptor properties in cerebellar stellate cells. J Neurosci 22:3881-3889.

Liu SQ, Cull-Candy SG (2000) Synaptic activity at calcium-permeable AMPA receptors induces a switch in receptor subtype. Nature 405:454-458.

Mayer ML, Armstrong N (2004) Structure and function of glutamate receptor ion channels. Annu Rev Physiol 66:161-181.

Mosbacher J, Schoepfer R, Monyer H, Burnashev N, Seeburg PL, Ruppersberg JP (1994) A molecular determinant for submillisecond desensitization in glutamate receptors. Science 266:1059-1062.

Nicoll RA, Tomita S, Bredt DS (2006) Auxiliary subunits assist AMPA-type glutamate receptors. Science 311:1253-1256.

Nielsen TA, DiGregorio DA, Silver RA (2004) Modulation of glutamate mobility reveals the mechanism underlying slow-rising AMPAR EPSCs and the diffusion coefficient in the synaptic cleft. Neuron 42:757-771.

Nusser Z, Naylor D, Mody I (2001) Synapse-specific contribution of the variation of transmitter concentration to the decay of inhibitory postsynaptic currents. Biophys J 80:1251-1261.

Otis T, Zhang S, Trussell LO (1996) Direct measurement of AMPA receptor desensitization induced by glutamatergic synaptic transmission. J Neurosci 16:7496-7504

Palay SL, Chan-Palay V (1974) Cerebellar cortex cytology and organization. New York: Springer.

Partin KM, Patneau DK, Mayer ML (1994) Cyclothiazide differentially modulates desensitization of alpha-amino-3-hydroxy-5-methyl-4-isoxazolepropionic acid receptor splice variants. Mol Pharmacol 46:129-138.

Patneau DK, Vyklicky Jr L, Mayer ML (1993) Hippocampal neurons exhibit cyclothiazide-sensitive rapidly desensitizing responses to kainate. J Neurosci 13:3496-3509.

Priel A, Kolleker A, Ayalon G, Gillor M, Osten P, Stern-Bach Y (2005) Stargazin reduces desensitization and slows deactivation of the AMPA-type glutamate receptors. J Neurosci 25:2682-2686.

Regehr WG, Mintz IM (1994) Participation of multiple calcium channel types in transmission at single climbing fiber to Purkinje cell synapses. Neuron 12:605-613.

Rigo JM, Badiu CI, Legendre P (2003) Heterogeneity of postsynaptic receptor occupancy fluctuations among glycinergic inhibitory synapses in the zebrafish hindbrain. J Physiol (Lond) 553:819-832.

Rizzoli SO, Betz WJ (2005) Synaptic vesicle pools. Nat Rev Neurosci 6:57-69.

Robert A, Howe JR (2003) How AMPA receptor desensitization depends on receptor occupancy. J Neurosci 23:847-858.

Rozov A, Jerecic J, Sakmann B, Burnashev N (2001) AMPA receptor channels with long-lasting desensitization in bipolar interneurons contribute to synaptic depression in a novel feedback circuit in layer $2 / 3$ of rat neocortex. J Neurosci 21:8062-8071.

Sakaba T, Neher E (2001) Calmodulin mediates rapid recruitment of fastreleasing synaptic vesicles at a calyx-type synapse. Neuron 32:1119-1131.

Sakaba T, Neher E (2003) Involvement of actin polymerization in vesicle recruitment at the calyx of Held synapse. J Neurosci 23:837-846.

Sara Y, Virmani T, Deak F, Liu X, Kavalali ET (2005) An isolated pool of vesicles recycles at rest and drives spontaneous neurotransmission. Neuron 45:563-573.

Sato K, Kiyama H, Tohyama M (1993) The differential expression patterns of messenger RNAs encoding non-N-methyl-D-aspartate glutamate receptor subunits (GluR1-4) in the rat brain. Neuroscience 52:515-539.

Satzler K, Sohl LF, Bollmann JH, Borst JG, Frotscher M, Sakmann B, Lubke JH (2002) Three-dimensional reconstruction of a calyx of Held and its postsynaptic principal neuron in the medial nucleus of the trapezoid body. J Neurosci 22:10567-10579.
Saviane C, Silver RA (2006) Fast vesicle reloading and a large pool sustain high bandwidth transmission at a central synapse. Nature 439:983-987.

Schlesinger F, Tammena D, Krampfl K, Bufler J (2005) Desensitization and resensitization are independently regulated in human recombinant GluR subunit coassemblies. Synapse 55:176-182.

Schneggenburger R, Sakaba T, Neher E (2002) Vesicle pools and short-term synaptic depression: lessons from a large synapse. Trends Neurosci 25:206-212.

Shepherd GM, Raastad M (2003) Axonal varicosity distributions along parallel fibers: a new angle on a cerebellar circuit. Cerebellum 2:110-113.

Silver RA, Cull-Candy SG, Takahashi T (1996) Non-NMDA glutamate receptor occupancy and open probability at a rat cerebellar synapse with single and multiple release sites. J Physiol (Lond) 494:231-250.

Singer JH, Diamond JS (2006) Vesicle depletion and synaptic depression at a mammalian ribbon synapse. J Neurophysiol 95:3191-3198.

Smith PH, Joris PX, Yin TC (1998) Anatomy and physiology of principal cells of the medial nucleus of the trapezoid body (MNTB) of the cat. J Neurophysiol 79:3127-3142.

Sommer B, Keinanen K, Verdoorn TA, Wisden W, Burnashev N, Herb A, Kohler M, Takagi T, Sakmann B, Seeburg PH (1990) Flip and flop: a cell-specific functional switch in glutamate-operated channels of the CNS. Science 249:1580-1585.

Spirou GA, Brownell WE, Zidanic M (1990) Recordings from cat trapezoid body and HRP labeling of globular bushy cell axons. J Neurophysiol 63 1169-1190.

Sudhof TC (2001) $\alpha$-Latrotoxin and its receptors: neurexins and CIRL/latrophilins. Annu Rev Neurosci 24:933-962.

Sudhof TC (2004) The synaptic vesicle cycle. Annu Rev Neurosci 27:509-547.

Sun JY, Wu LG (2001) Fast kinetics of exocytosis revealed by simultaneous measurements of presynaptic capacitance and postsynaptic currents at a central synapse. Neuron 30:171-182.

Thach WT (1968) Discharge of Purkinje and cerebellar nuclear neurons during rapidly alternating arm movements in the monkey. J Neurophysiol 31:785-797.

Tong G, Jahr CE (1994) Block of glutamate transporters potentiates postsynaptic excitation. Neuron 13:1195-1203.

Trussell LO, Zhang S, Raman IM (1993) Desensitization of AMPA receptors upon multiquantal neurotransmitter release. Neuron 10:1185-1196.

Turetsky D, Garringer E, Patneau DK (2005) Stargazin modulates native AMPA receptor functional properties by two distinct mechanisms. J Neurosci 25:7438-7448.

Ushkaryov YA, Volynski KE, Ashton AC (2004) The multiple actions of black widow spider toxins and their selective use in neurosecretion studies. Toxicon 43:527-542.

van Kan PL, Gibson AR, Houk JC (1993) Movement-related inputs to intermediate cerebellum of the monkey. J Neurophysiol 69:74-94.

von Gersdorff H, Borst JG (2002) Short-term plasticity at the calyx of held. Nat Rev Neurosci 3:53-64.

von Gersdorff H, Matthews G (1997) Depletion and replenishment of vesicle pools at a ribbon-type synaptic terminal. J Neurosci 17:1919-1927.

von Gersdorff H, Matthews G (1999) Electrophysiology of synaptic vesicle cycling. Annu Rev Physiol 61:725-752.

Wadiche JI, Jahr CE (2001) Multivesicular release at climbing fiberPurkinje cell synapses. Neuron 32:301-313.

Wong AY, Graham BP, Billups B, Forsythe ID (2003) Distinguishing between presynaptic and postsynaptic mechanisms of short-term depression during action potential trains. J Neurosci 23:4868-4877.

Xu-Friedman MA, Regehr WG (2003) Ultrastructural contributions to desensitization at cerebellar mossy fiber to granule cell synapses. J Neurosci 23:2182-2192.

Xu-Friedman MA, Regehr WG (2004) Structural contributions to shortterm synaptic plasticity. Physiol Rev 84:69-85.

Xu-Friedman MA, Harris KM, Regehr WG (2001) Three-dimensional comparison of ultrastructural characteristics at depressing and facilitating synapses onto cerebellar Purkinje cells. J Neurosci 21:6666-6672.

Yamada KA, Tang CM (1993) Benzothiadiazides inhibit rapid glutamate receptor desensitization and enhance glutamatergic synaptic currents. J Neurosci 13:3904-3915.

Zucker RS, Regehr WG (2002) Short-term synaptic plasticity. Annu Rev Physiol 64:355-405. 